\title{
Models, solution, methods and their applicability of dynamic location problems (DLPs) (a gap analysis for further research)
}

\author{
Seyed Mohammad Seyedhosseini ${ }^{1} \cdot$ Ahmad Makui $^{1} \cdot$ Kamran Shahanaghi $^{1}$. \\ Sara Sadat Torkestani ${ }^{1}$
}

Received: 19 January 2016/ Accepted: 24 April 2016/Published online: 28 May 2016

(c) The Author(s) 2016. This article is published with open access at Springerlink.com

\begin{abstract}
Determining the best location to be profitable for the facility's lifetime is the important decision of public and private firms, so this is why discussion about dynamic location problems (DLPs) is a critical significance. This paper presented a comprehensive review from 1968 up to most recent on published researches about DLPs and classified them into two parts. First, mathematical models developed based on different characteristics: type of parameters (deterministic, probabilistic or stochastic), number and type of objective function, numbers of commodity and modes, relocation time, number of relocation and relocating facilities, time horizon, budget and capacity constraints and their applicability. In second part, It have been also presented solution algorithms, main specification, applications and some real-world case studies of DLPs. At the ends, we concluded that in the current literature of DLPs, distribution systems and production-distribution systems with simple assumption of the tackle to the complexity of these models studied more than any other fields, as well as the concept of variety of services (hierarchical network), reliability, sustainability, relief management, waiting time for services (queuing theory) and risk of facility disruption need for further investigation. All of the available categories based on different criteria, solution methods and applicability of them, gaps and analysis which have been done in this paper suggest the ways for future research.
\end{abstract}

Seyed Mohammad Seyedhosseini seyedhosseini@iust.ac.ir

1 Department of Industrial Engineering, Iran University of Science and Technology, Tehran, Iran
Keywords Facility location - Dynamic $\cdot$ Dynamic location problems (DLPs) · Time horizon · Review

\section{Introduction}

The purpose of this paper is to review some of the DLPs research which has contributed to the current state-of-theart and fills the gap in the literature. The focus is on the classification of current mathematical models, solution methods and applications available in the literature. Our objective is to provide a survey of dynamic location problems in the different fields of facility location.

Selecting the best location of facilities or new facilities is an important function in time horizon. Before determining the place of facilities, the profitable locations should be selected, the capacity of it defined and amount of budget should be specific. Hence, high costs of this process is problematic for every location in regard to a long-term planning and investing. Regarding planning for future conditions and also large amount of budget that is needed to establish a facility, selecting a location should be in a way that the facility could be efficient and accessible in time horizon (Owen and Daskin 1998).

The strategic nature of facility location problems necessitate some aspect of future uncertainty to be considered in models. Due to the broader researches in location and relocation problems, decision makers selected the locations that can be effective for a time period, relocations over the long term, timing of facility expanded and changing demands that occur during the time simultaneously. Therefore, decision makers should select places that are not only ideal for current condition of system but also stay useful for all the time. Here is where the essence of dynamic location problems, considering time in modeling, 
appears [Owen and Daskin (1998); Farahani and Hekmatfar (2009) and Farahani et al. (2009)].

In general, decision maker selects the site which would be useful for a time horizon in time-dependent location problems but in location-relocation problems after selecting a primary location, relocation times improved facility's location regarding conditions for a defined time horizon (Farahani et al. 2009).

Current et al. (1997) divided the models of dynamic location problems into two categories: explicitly dynamic and implicitly dynamic. In implicitly dynamic problems, all the facilities open at the same time and will be open during the time horizon. This category of problems seems to be static conceptually but as the problem parameters can change during the planning horizon, they are considered as dynamic location problems. In explicitly dynamic problems, unlike implicitly dynamic problems, facilities can be opened or closed several times for a defined time horizon.

The first survey of DLPs backs to the work of Owen and Daskin (1998) presenting the model of integer programming, dynamic programming, stochastic programming and scenario planning techniques. Farahani and Hekmatfar (2009) developed a framework and classified the models formulation and solution technique of DLPs. In addition, Arabani and Farahani (2012) surveyed the static and dynamic facility location problems and classified DLPs models to the several parts, then discussed about mathematical models, solution methods and applications of the available research in the literature since 2011.

There have been some motivation and contribution of our review paper based on the analysis of the previous research as follows:

- According to the papers that have been reviewed, the most recent review paper in DLPs is the work of Arabani and Farahani (2012) discussed about 30 years from 1981 to 2011. Our paper presents modeling effort including those published after 2011, and review about 47 years of DLPs from 1968 until October 2015.

- In the available review paper, all of the main elements of facility location dynamic problems are studied before 2011. Our paper presents a broader review of these research including those published after 2011, also we have been investigating the new elements in DLPs called the Dynamic Hub Facility Location Problems (DHFLPs).

- We consider a wide range of characteristics for classification of the current and available DLPs research in the literature. Such characteristics as the number of objective, facilities and commodity, budget limits, capacity limits, number of relocation, type of parameters, facility and objectives and configuration have never been used in the past for classification the researches, so these detailed characteristics for categorizing the DLPs are comprehensively discussed in this review paper (Tables 1, 2).

- Most of the review papers in DLPs emphasize on categorizing DLPs model without adequate attention on the application of solution method used. We discussed this gap in the current paper.

- To the future research, the implementation of reliability, sustainability, different levels of services, planning for global logistics, relief management in crisis, queuing theory and risk of disruption needs to be taken into account as new recent trends and contributions in DLPs and these subjects are discussed more in conclusion section.

The emphasis of this review paper is on previously analyzed papers based on the available review research in the DLPs modelling efforts and gives us insight into some uncovered aspects in this field that have been published after 2009.

To search about the relevant paper in dynamic location problems, the only database such as sciencedirect and google scholar have been utilized. The keywords "Dynamic" AND "Facility" AND "Location" AND "Time Horizon" get us 107 research in this field. 45 different journals have been found based on these keywords about the above-mentioned researches. According to our investigation, most of these papers are published in "Computers \& operations research", "Computers \& Industrial Engineering" and "European Journal of Operational Research". We found the last published research in DLPs models before October 2015. All of mentioned aspects have been the scope and limitations of this review research.

This review paper is categorized as follows. In the next section, an assortment of DLPs based on their performance measure of the available literature such as number of facility, objective functions, commodity, parameters, configuration, relocation time, time horizon, applications and etc. will be provided. At the beginning of Sect. 3, a brief introduction of static facility location research is presented as a background for the review and then highlighted contributions in DLPs model formulation will be reviewed in 8 parts and the expansion trends of each part will be discussed. In Sect. 4, solution methods of DLPs is presented in two parts: (1) exact solution, and (2) heuristic, uncertain method and metaheuristic solution, regarding these two parts the solution techniques of accessible literature will be discussed. Section 5 addresses the application of DLPs models in terms of solution methods, industrial fields and real-world case studies. Finally, Sect. 6 suggests directions of future research and presents the conclusion of the whole review paper based on the current literature. 
Table 1 Characteristics used for classification of the published models

\begin{tabular}{|c|c|c|c|c|c|}
\hline \multirow[t]{26}{*}{ Objective functions (min) } & $\mathrm{FC}$ & Fixed cost & Number of & SO & Single objective \\
\hline & $\mathrm{TC}$ & Transportation cost & objectives & MO & Multiple objective \\
\hline & $\mathrm{CC}$ & Close cost & Parameters & Det & Deterministic \\
\hline & ROC & Reopening cost & & Pro & Probabilistic \\
\hline & $\mathrm{IHC}$ & Inventory holding cost & & Sto & Stochastic \\
\hline & PC & Productive cost & & Fuz & Fuzzy \\
\hline & $\mathrm{MC}$ & Maintenance cost & Facilities & Ex & Exogenous \\
\hline & RouC & Routing cost & & En & Endogenous \\
\hline & $\mathrm{EC}$ & Expansion cost & Number of facilities & $\mathrm{S}$ & Single \\
\hline & REDC & Reduction cost & & M & Multiple \\
\hline & $\mathrm{RC}$ & Relocation cost & Configuration & HUN & Hub network \\
\hline & $\mathrm{BC}$ & Backorder cost & & HIN & Hierarchical network \\
\hline & $\mathrm{NF}$ & Number of facility & & - & Other \\
\hline & TRC & Treatment cost & Relocation time & DT & Discrete time \\
\hline & SUC & Subcontracting cost & & $\mathrm{CT}$ & Continuous time \\
\hline & SHC & Shortage cost & Time horizon & $\mathrm{F}$ & Finite \\
\hline & LC & Labor cost & & INF & Infinite \\
\hline & HR & Human population centers risk & Capacity constraint & $\mathrm{L}$ & Limited \\
\hline & NHR & $\begin{array}{l}\text { Nonhuman population centers } \\
\text { risk }\end{array}$ & & $\mathrm{E}$ & Capacity expansion \\
\hline & PENCS & Penalty cost for services & & $\mathrm{R}$ & Capacity reduction \\
\hline & $\mathrm{AC}$ & Adding facility cost & & $\mathrm{P}$ & Production capacity \\
\hline & $\mathrm{NCovC}$ & Non coverage cost & & $\mathrm{U}$ & Unlimited \\
\hline & $\mathrm{UC}$ & Unused facility cost & Applications & $\mathrm{CO}$ & Competitive systems \\
\hline & PUC & Punishment cost & & DI & Distribution systems \\
\hline & TT & Travel time & & ED & Education \\
\hline & $\mathrm{SeC}$ & Service cost & & EMS & Emergency medical systems \\
\hline \multirow[t]{2}{*}{ Objective functions (max) } & $\mathrm{P}$ & Profit & & HS & Hub systems \\
\hline & Cov & Coverage & & $\mathrm{PD}$ & Production-distribution systems \\
\hline \multirow[t]{3}{*}{$\begin{array}{l}\text { Objective functions (min- } \\
\max \text { ) }\end{array}$} & LEE & Load of established emergency & & SWM & $\begin{array}{l}\text { Solid waste management } \\
\text { systems }\end{array}$ \\
\hline & Risk & Risk & & $\mathrm{TN}$ & Telecommunications networks \\
\hline & Regret & Regret & & & \\
\hline
\end{tabular}

\section{Classification of modeling efforts}

Locating of facilities is one of the important aspects of strategic planning for widespread of private and public companies. Changes in population, market size and other environmental factors guarantee new planning challenges (new locating requirement and relocation) that is why, in an organization, planning is done in a way that facilities can be profitable for a period of time and be efficient during their life span. As a result, time changing is a necessary matter that must be considered (Owen and Daskin 1998).

Generally, one can study facility location problem based on essence of matter and used parameters are classified into two types: (1) certainty and uncertainty, (2) sustainability and unsustainability.
In general, dynamic location problems can be divided into several types based on different criteria such as cause of change, the number of relocations, the number of relocating facilities, relocation time and the time horizon. Classification of dynamic location problems based on these characteristics and the modeling discussed in this review paper are demonstrated in Fig. 1.

First, the available classification in dynamic facility location problems adopted for the literature have been presented, then according to the structures proposed in the literature, as a result of reviewing the literature the integration and merging of these categories have been provided and discussed.

To provide different characteristics (criteria) for classifications of dynamic location problems, some of following definitions and different criteria will be presented: 


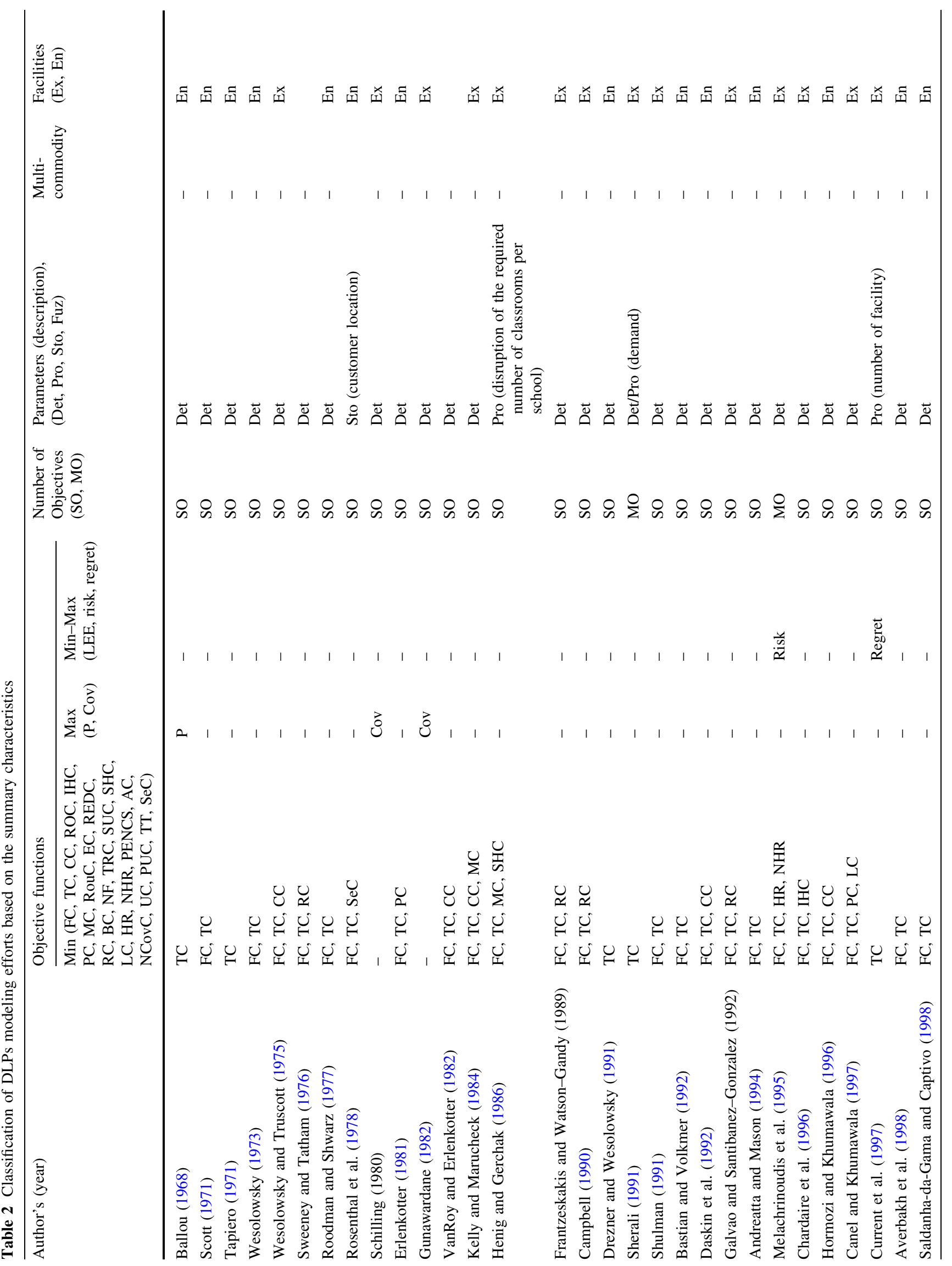




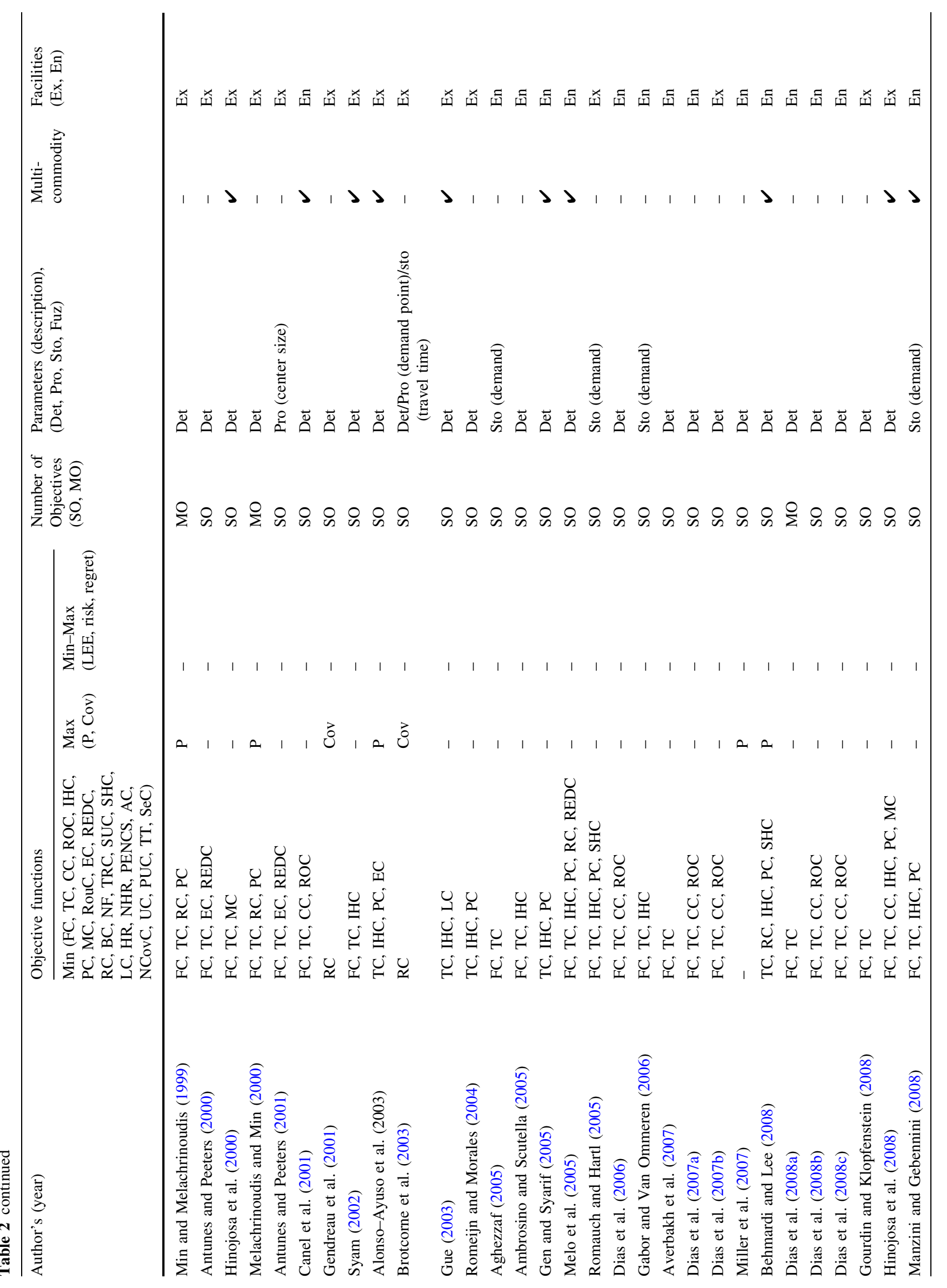




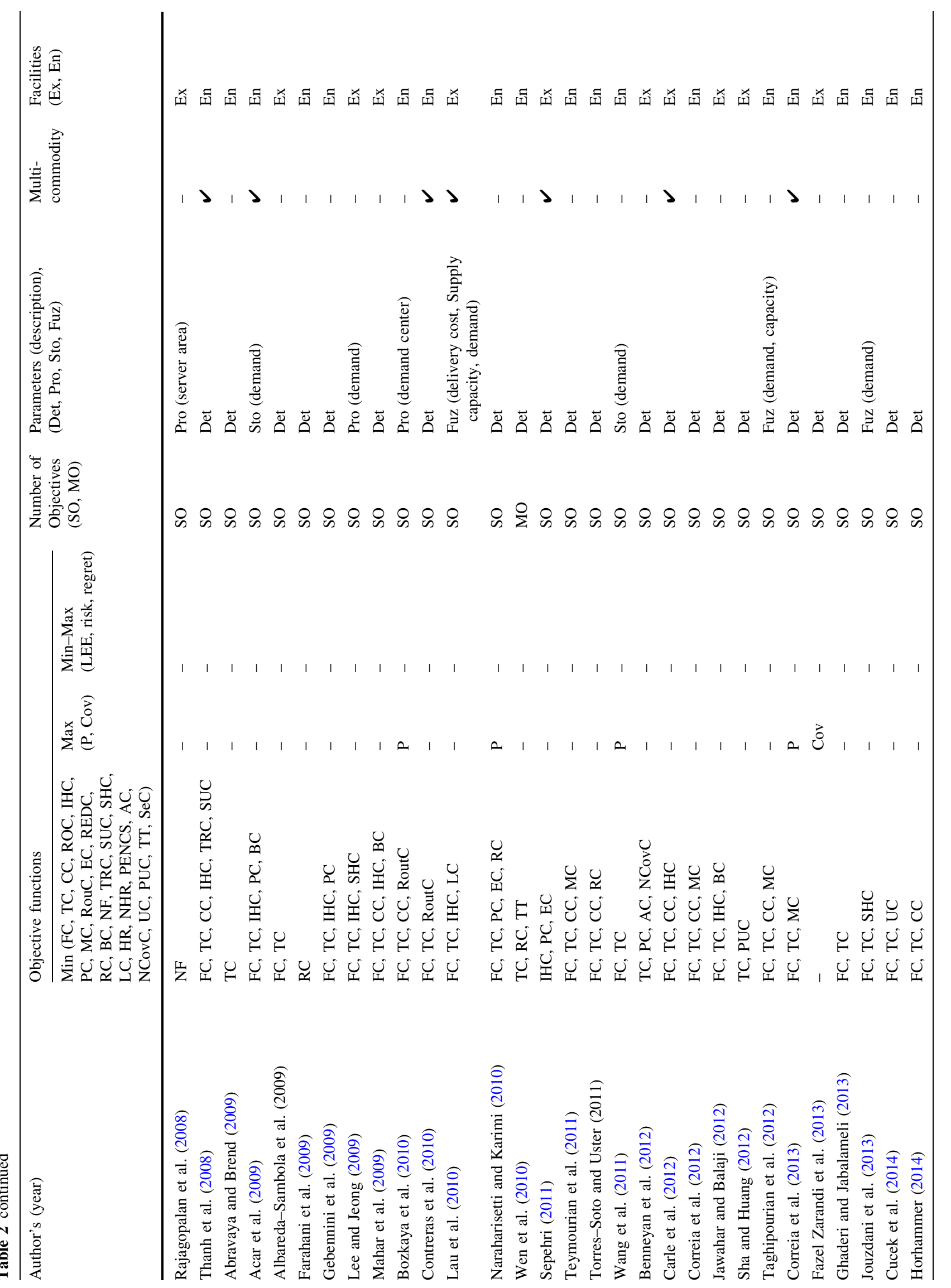




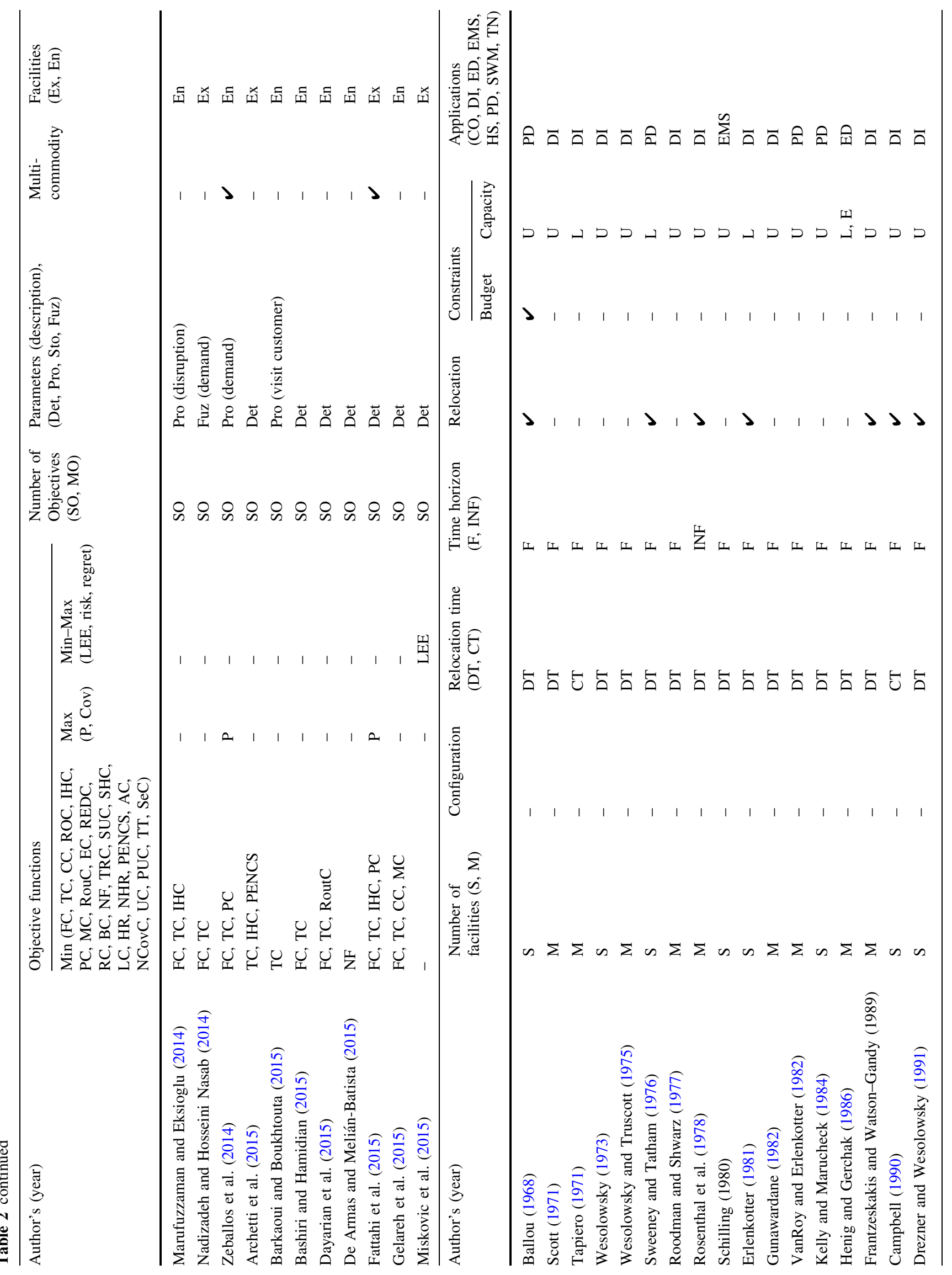




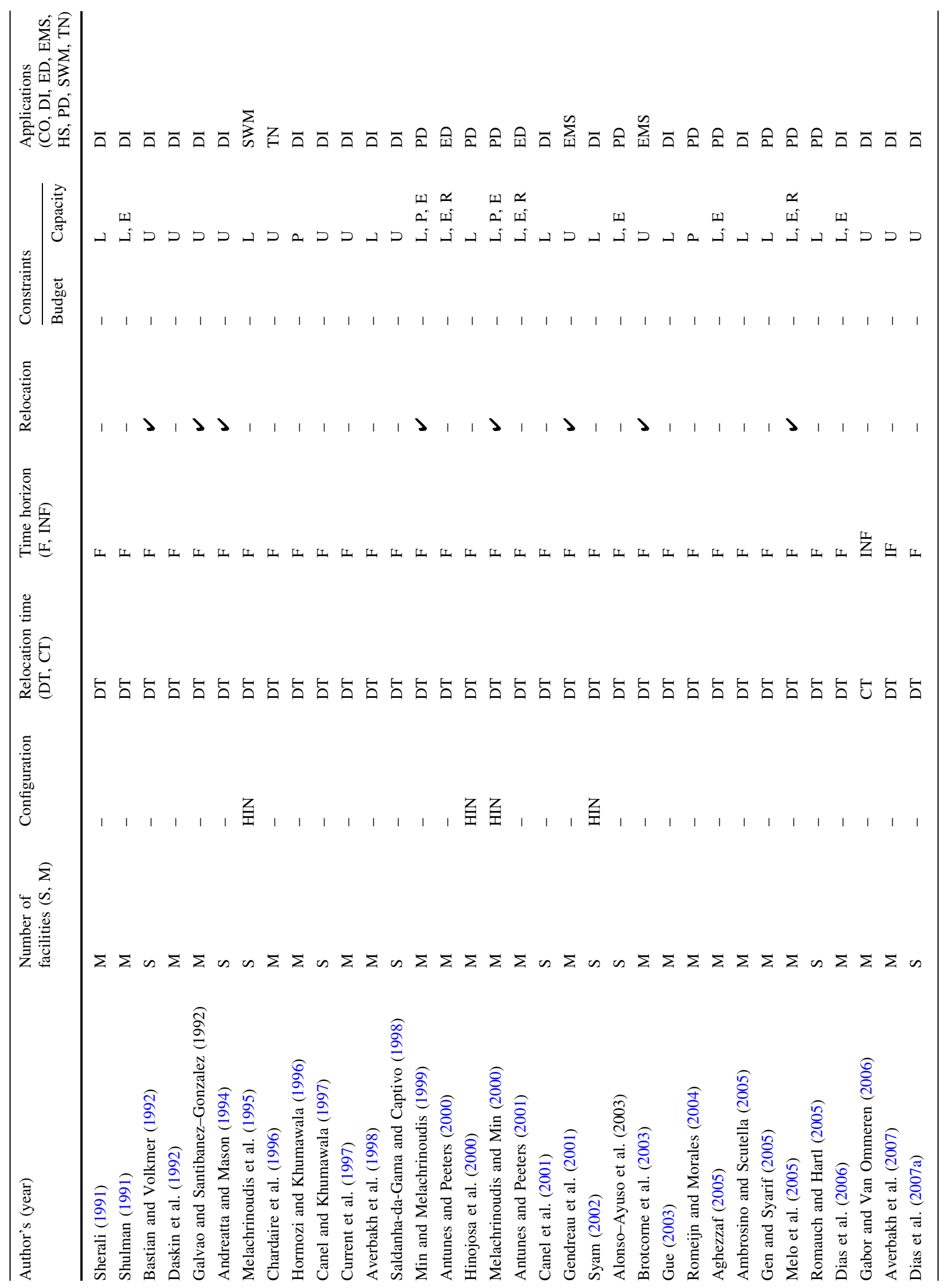




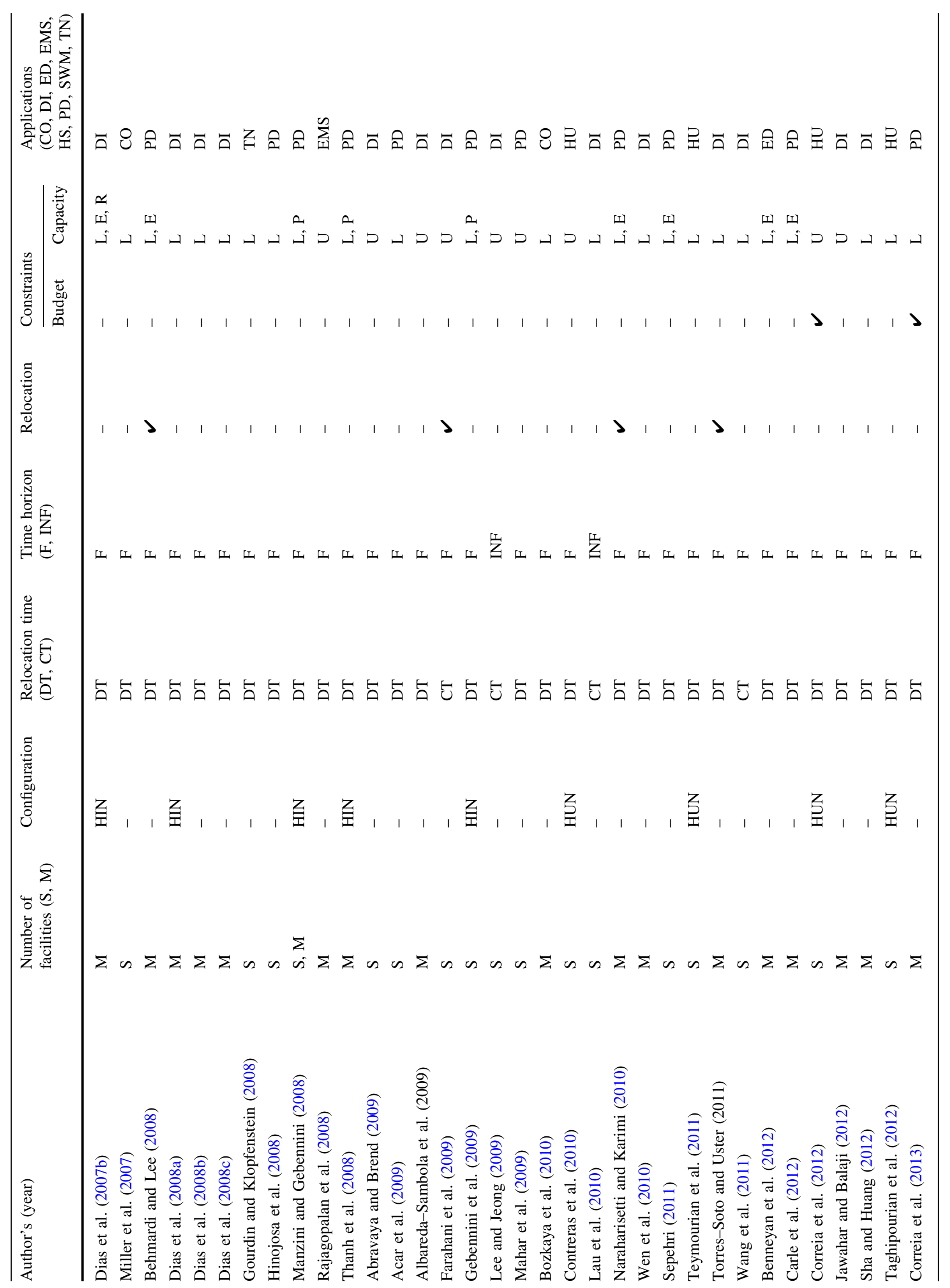




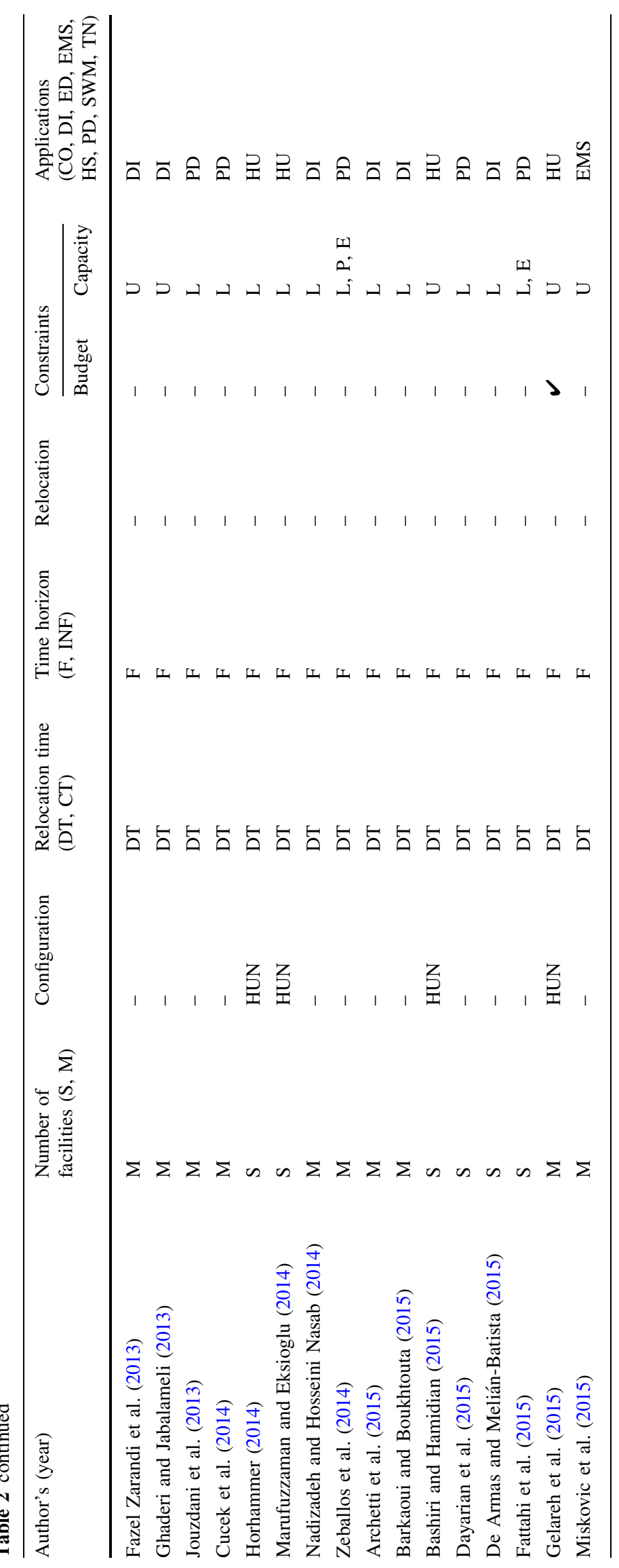




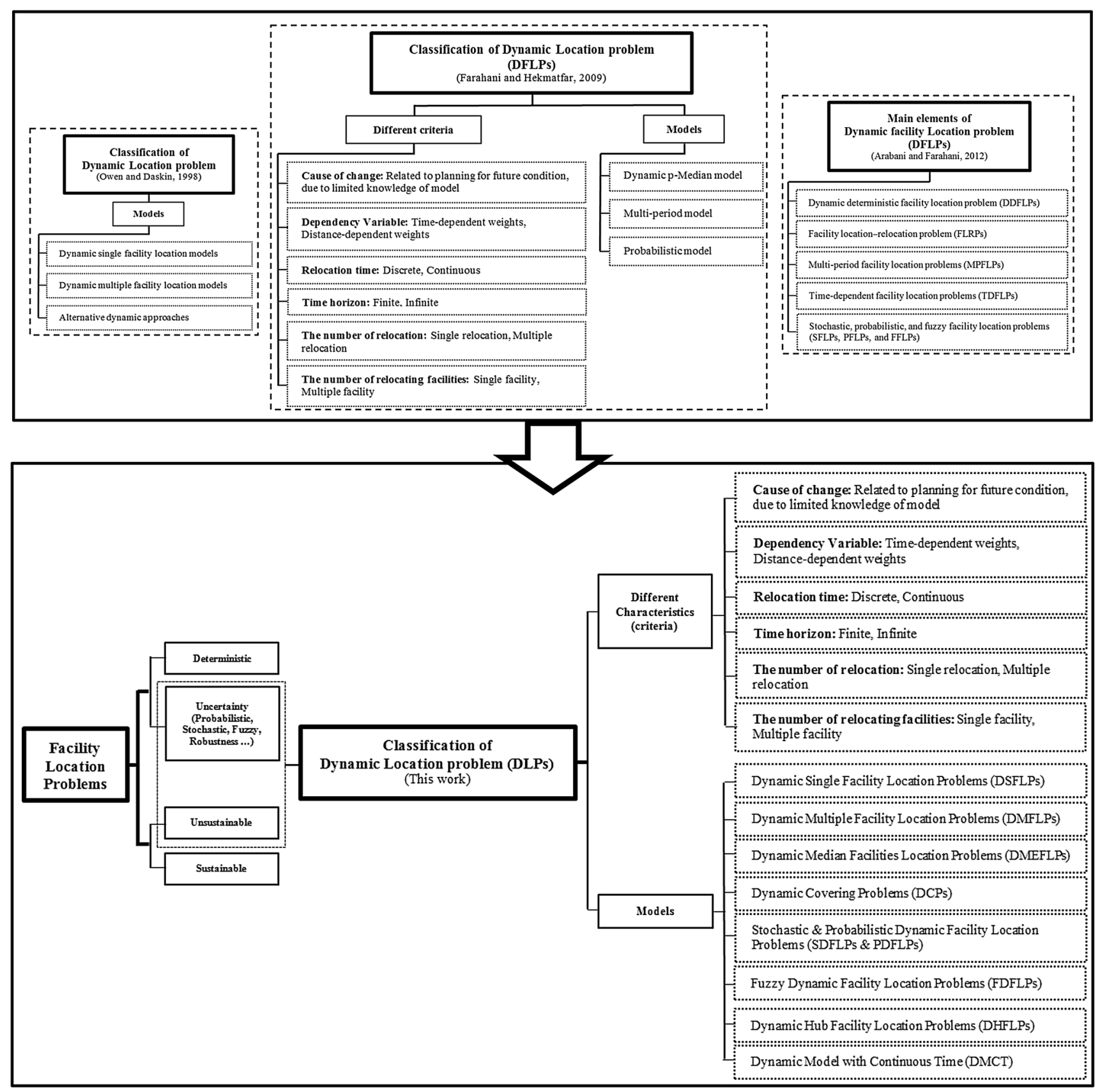

Fig. 1 Classification of dynamic location problems (DLPs)

Cause of change The most important classification is based on the cause of uncertainty that is classified two categories. (1) Changing because of future conditions, (2) Pattern of changes because of uncertainty due to limited knowledge of model input parameters (Rosenthal et al. 1978 and Owen and Daskin 1998).

One should consider that although in first category, changes exist but it is assumed that it is changing with deterministic and time-dependent parameters and has a distinctive pattern of change. But in the second category, it is possible that the pattern of changes is stochastic and it is not time dependent (Farahani et al. 2009).

Number and type of objective functions In dynamic location problems, number and type of models can be as follows: single objective or multi-objective, bi-level or multi-level, two-stage or multi-stage (Farahani et al. 2014).

Parameters According to the type of parameters used, models in dynamic location problems (DLPs) are categorized as deterministic, probabilistic, stochastic or fuzzy (Farahani et al. 2014). 
Number of commodity and vehicle In a network, it is possible for commodity and vehicle to be more than one.

Facilities Exogenous and endogenous. In location problems, if the number of facilities that needs to be located is predetermined at each level, the model will be exogenous and if the optimal number is to be found by solving the model, it is an endogenous model (Farahani et al. 2014).

Levels and type of network The number of levels (types of services) can be variable in a system. In most of studied models, the network is only considered by one specific type of service, while in hierarchical location problems, different number of service levels are considered. However, dynamic location problems can be studied in different and multi-levels of services and the network type can be designed as hub network (Farahani et al. 2014).

Relocation time Discrete and continuous. In the first category, relocation is only possible in discrete points (predeterministic points) of time (Wesolowsky 1973); however, in the second category, almost any time of planning horizon and relocation is possible (Drezner and Wesolowsky 1991).

Time horizon Finite and infinite. Solving the dynamic location problems (DLPs) is due to uncertainty of future conditions. Postponing decision making as much as possible to collect information and improve forecasts is the best solution to manage uncertainty. This is why considering a time horizon is necessary in modeling. In addition, the main objective of dynamic location planning is not to determine location or relocation for the whole time horizon, but it is to find an optimum or near optimum for first period solution during the infinite horizon, hence whether the time horizon is finite or infinite, affects the decision of some aspects of the model (Daskin et al. 1992).

The number of relocation Single relocation and multiple relocation. In the single relocation, relocation is allowed in time horizon just once and in multiple relocations, new facilities are allowed to locate and change them more than once during the time horizon (Emamizadeh and Farahani 1997a, 1997b).

The number of relocating facilities Single facility and multiple facilities. In single facility, it is allowed to relocate only one facility during the time horizon whereas in the second category, it is allowed to relocate more than one facility during the planning horizon (Scott 1971 and Owen and Daskin 1998).

Constraints Limited and unlimited. Capacity of facility, rout, vehicle and reachable amount of budget in location problems can be limited or unlimited. Also capacities can expand or reduce in planning horizon (Farahani et al. 2014).

Application Application of model is investigated based on the real-world case studies. Some of the applications of dynamic location problems (DLPs) modeling consist of competitive systems, distribution systems, education, Emergency Medical Systems (EMS), hub systems, production-distribution systems, solid waste management systems and telecommunications networks (Farahani et al. 2014).

Appliqué particulars which are used to categorize published dynamic location problem (DLP) articles are shown in Table 1. Dynamic location problem (DLP) models are sorted based on their year of publication in ascending order since 1968 until now to clearly demonstrate the trend of this evolution (Table 2).

The cause of tree (CT) structure has been presented for the DLPs investigation, so that Table 1 is considered as a prerequisite for Table 2 and the characteristics used for classification in this table are complementary to Table 2. All entire assortments in Table 2 are sorted through prerequisite mentioned in Table 1.

The classifications in Table 2 are based on dynamic location problem (DLP) properties and provide some important insights:

1. According to probabilistic and stochastic nature and essence of dynamic location problems (DLPs), in most of the research on this matter, there has been emphasis on the use of deterministic parameters. Assuming a problem as a probabilistic or stochastic is the most important cause of problem complexity and its solution. So for simpler solution, the parameters are taken as they are deterministic ones.

2. Mostly to simplify the problem in the literature, number of commodity and levels of services are considered as single commodity and level, but in every system a variety of commodity and services (levels of network) can be found.

3. As it can be seen, mathematical model complexity is cause of using discrete times of relocations to simplify the objective function of problem in all of the studies; however, choosing the continuous time of relocations causes to show the rather real situation.

4. Until recently, assuming dynamic location problem (DLP) budget an unlimited parameter has been the norm; however, in the past recent years, choosing a specific budget has helped us to be closer to real world.

\section{Basic dynamic location models}

Facility location problems can be divided into two categories: static and dynamic problems (Farahani and Hekmatfar 2009).

Based on the previous dynamic facility location review papers such as Owen and Daskin (1998) and Arabani and 
Farahani (2012), at the start of this section, a brief introduction of static facility location research will be presented as a background for the review, better understanding of the change between the static and dynamic models, then highlighted contributions in DLPs model formulation will be reviewed in 8 parts and the expansion trend of each part will be discussed.

At the beginning, static model will be studied in this part and then, according to classification in part (2.1), it is now possible to present various mathematical models to formulate dynamic location problems (DLPs). The most common modeling, which has been applied by the literature, will be introduced in detail.

Static location models, first time was presented by Weber problem in 1909 to find a location of facility between the facilities to be located at $(x, y)$ among $\mathrm{m}$ points of demand (destinations) located at $\left(a_{i}, b_{i}\right)$. The objective was to minimize the distance between the facility and costumers; transportation costs are assumed to be adequate to distance (Wesolowsky 1973).

$d_{i}(x, y)$ is the distance between the facility to be located at $(x, y)$ and destination i located at $\left(a_{i}, b_{i}\right) ; w_{i}$ a constant transforming distances into costs.

Location of facility is found by solving the following model (Wesolowsky 1973):

Minimize $\sum_{i=1}^{m} w_{i} \cdot d_{i}(x, y)$

Objective function (1) minimizing the distance between the facility and customers.

All of static location models can be argued in dynamic form as well. In dynamic location problem, there are two main criteria for decision making which make it easier to choose location. (1) Cost of new facilities or relocating the old ones in the time horizon. (2) Opening and closing time of facilities (Arabani and Farahani 2012).

There are also two important subsets in dynamic location problems: (1) in implicitly dynamic problems all facilities will be opened at the same time and will be active during the whole planning horizon. These problems seem to be static in the content but as parameters of problem could change in time horizon, they are considered dynamic problem. (2) Explicitly dynamic problems are the second part which, despite the implicitly dynamic problems, facilities can be opened or closed during the time horizon (Current et al. 1997).

Dynamic location problem has several mathematic models. Some of them which are explained in this literature consist of dynamic single facility location problems (DSFLPs), dynamic multiple facility location problems (DMFLPs), dynamic facilities location-allocation problems (DFLAPs), dynamic median facilities location problems (DMEFLPs), dynamic covering problems (DCPs), alternative dynamic approaches contains both stochastic \& probabilistic dynamic facility location problems (SDFLPs \& PDFLPs) and fuzzy dynamic facility location problems (FDFLPs), dynamic hub facility location problems (DHFLPs) and dynamic model with continuous time (DMCT).

\section{Dynamic single facility location problems (DSFLPs)}

Demands, costs and destination locations are forecasted with considering the time horizon of $\mathrm{r}$ discrete time periods, the static model (1) can be simplified and extended. Finding an optimal location of new facility in each period is the goal. The transportation costs of facility are independent of the distance of the facility they were transported (Wesolowsky 1973 and Farahani and Hekmatfar 2009).

$m_{k}$ is the number of destinations in period $k ; f_{k i}\left(x_{k}, y_{k}\right)$ the present value of the cost of shipping from the facility in period $k$ to destination $i ; C_{k}$ the cost of moving at the beginning of period $k ; d_{k-1, k}$ the distance the facility is moved at the beginning of period $k . Z_{k}$-if $\left(d_{k-1, k} \neq 0\right)$, set $Z_{k}=1$, otherwise, set $Z_{k}=0$.

Location of facility is found by solving the following model (Wesolowsky 1973):

Minimize $\sum_{k=1}^{r} \sum_{i=1}^{m_{k}} f_{k i}\left(x_{k}, y_{k}\right)+\sum_{k=2}^{r} C_{k} Z_{k}$

\section{Dynamic multiple facility location problems (DMFLPs)}

Multi-period location allocation modeling is a problem that locates $\mathrm{G}$ new facilities among $\mathrm{M}$ candidate site to provide $\mathrm{N}$ demand points during the time horizon. This model proposed to find the optimal locations and relocations for response changing the demand over the planning horizon of $k$ periods (Wesolowsky 1973 and Farahani and Hekmatfar 2009).

$A_{j i k}$ is the present value of the cost of assigning node $i$ to node $j$ in period $k ; C_{j k}^{\prime}$ the present value of the cost of removing a facility from site $j$ in period $k$; $C_{j k}^{\prime \prime}$ the present value of the cost of establishing a facility at site $j$ in period $k ; m_{k}$ the maximum number of facility location changes allowed in period $k$.

$x_{j i k}$-if node $i$ is assigned to node $\mathrm{j}$ in period $k$, set $x_{j i k}=1$, otherwise, set $x_{j i k}=0 ; y_{j k}^{\prime}$-if a facility is removed from site $j$ in period $k$, set $y_{j k}^{\prime}=1$, otherwise, set $y_{j k}^{\prime}=0 ; y_{j k}^{\prime \prime}$-if a facility is established at site $j$ in period $k$, set $y_{j k}^{\prime \prime}=1$, otherwise, set $y_{j k}^{\prime \prime}=0$. 
Objective function and constraints of the problem can thus be formulated as follows [Wesolowsky (1973) and Farahani and Hekmatfar (2009)]:

Minimize $\quad \sum_{k=1}^{K} \sum_{i=1}^{N} \sum_{j=1}^{M} A_{j i k} x_{j i k}+\sum_{k=2}^{K} \sum_{j=1}^{M}\left(C_{j k}^{\prime} y_{j k}^{\prime}+C_{j k}^{\prime \prime} y_{j k}^{\prime \prime}\right)$

Subject to:

$$
\begin{aligned}
& \sum_{j=1}^{M} x_{j i k}=1 \quad \forall i, k \\
& \sum_{i=1}^{N} x_{j i k} \leq N x_{j j k} \quad \forall j, k \\
& \sum_{j=1}^{M} x_{j i k}=G \quad \forall k \\
& \sum_{j=1}^{M} y_{j k}^{\prime} \leq m_{k} \quad \forall k \geq 2 \\
& x_{j j k}-x_{j j, k-1}+y_{j k}^{\prime}-y_{j k}^{\prime \prime}=0 \quad \forall j, \quad k \geq 2 \\
& x_{j i k} \geq 0 \quad \forall i \neq j ; \\
& y_{j k}^{\prime}, y_{j k}^{\prime \prime} \geq 0 \quad \forall j, k ; \\
& x_{j j k}=\{0,1\} \quad \forall j, k
\end{aligned}
$$

Constraint (4) demonstrated single allocation. Constraint (5) guarantees that point $i$ is assigned to facility $j$, when the facility is established in node $j$. Constraint (6) and (7) ensure that in each period, $G$ facility can be established and the maximum number of changes allowed for facilities should be less than the $m_{k}$. As G number of facilities can be built in each period, Constraint (8) represents an equilibrium limit to establish the mentioned assumption. Constraint (9) is decision variables of problem.

\section{Dynamic facilities location allocation problems (DFLAPs)}

Location allocation problems are not only to find the best place for facilities but also to allocate facilities to customers to satisfy their demands optimally (Arabani and Farahani (2012). Discrete DFLPS was first studied by Scott (1971), and then Wesolowsky (1973) and Wesolowsky and Truscott (1975) expanded dynamic single facility location problems and dynamic multiple facility location problems.

Daskin et al. (1992) studied future effects of uncertainty in DFLAPS conditions and the main aim was not to consider the location and relocation in time horizon but to find an optimum or near-optimum solution for the first period. The research of Chardaire et al. (1996) was on demand changes in multi-period in DFLAPs. Saldanha da Gama and Captivo (1998) worked on improving heuristic solution approach. Antunes and Peeters (2000) studied education network planning model with changing general facilities capacity and then in the next year a new solution was established. Averbakh et al. (2007) worked on expanding the dynamic programming algorithm.

Planning and designing logistic distribution system in different dynamic levels by Manzini and Gebennini (2008), an integrated production-distribution model for the dynamic location and allocation problem with safety stock optimization by Gebennini et al. (2009) and DFLAPs in health department of veterans by Benneyan et al. (2012) were presented.

\section{Dynamic median facilities location problems (DMEFLPs)}

Extension of p-median model, from 1-median problem was the most important part of median; it was made to find the best location for $\mathrm{p}$ facilities to minimize the sum distance for every point of demand to closest facility (Arabani and Farahani 2012).

Dynamic location problem applying a scenario planning is presented in this section. Regarding the description of the model, the objective function minimizes expected regret. All of the scenarios and candidate location for new facilities are predetermined and common. The probability of each scenario should be estimated based on information and having different scenarios make the demand assignments in each scenario be different to the other one (Owen and Daskin 1998).

$k$ is the index of possible scenarios; $P$ the number of new facility; $h_{i k}$ demand at node i under scenario $k ; d_{i j k}$ distance from node $i$ to facility site $j$ under scenario $k$; $\hat{v}_{k}$ optimal $P$ median solution value for scenario $k ; q_{k}$ scenario probability for scenario $k ; R_{k}$ the regret associated with scenario $k,\left(R_{k}=v_{k}-\hat{v}_{k}\right)$.

$y_{i j k}$-if demand node $i$ is assigned to facility $j$ under scenario $k$, set $y_{i j k}=1$, otherwise, set $y_{i j k}=0 ; x_{j}$-if facility site $j$ locates at potential, set $x_{j}=1$, otherwise, set $x_{j}=0 . v_{k}$, under the conditions of compromise locations:

$v_{k}=\sum_{i} \sum_{j} h_{i k} d_{i j k} y_{i j k}$

Objective function and constraints of the problem will be as below (Owen and Daskin 1998):

Minimize $\sum_{k} q_{k} R_{k}$

subject to: 
$\sum_{j} x_{j}=P$

$\sum_{j} y_{i j k}=1 \quad \forall i, k$

$y_{i j k}-x_{j} \leq 0 \quad \forall i, j, k$

$R_{k}-\sum_{i} \sum_{j}\left(h_{i k} d_{i j k} y_{i j k}-\hat{v}_{k}\right)=0 \quad \forall k$

$y_{i j k}=\{0,1\} \quad \forall i, j, k$

$x_{j}=\{0,1\} \quad \forall j$

Constraint (11) represents the maximum number of new facilities to be located. Constraint (12) point $i$, under scenario $k$ will be definitely supplied by facility $j$. Constraint (13) guarantees that in scenario $k$, demand $i$ can be assigned to facility $j$ when facility was opened. Constraint (14) demonstrates the regret of scenario $k$. Constraint (15) and (16) are decision variables.

Wesolowsky (1973) was the first one who studied DMEFLPs. Erlenkotter (1981) tried to develop the algorithms for DMEFLPs. Drezner and Wesolowsky (1991) studied multi-relocation in time horizon while maximum expected cost lows down to minimum. Shulman (1991) presented a schedule to setup facilities in location, to minimize costs during the time horizon. Galvao and Santibanez-Gonzalez (1992) studied a heuristic approach to solve dynamic p-median problem. Current et al. (1997) developed DMEFLPs for conditions which number of facilities is unknown; also changing the size of facilities and dependency of setup cost to number of customers were studied by Averbakh et al. (1998).

Dias et al. (2006) have established DMEFLPs in three different scenarios. Averbakh et al. (2007), Dias et al. (2008a), Dias et al. (2008b), Albareda-Sambola et al. (2009) worked on developing the model and presenting a new solution. Farahani et al. (2009) studied single facility with multi-relocation in which weight of demand point is dependent on time.

\section{Dynamic covering problems (DCPs)}

In general, every customer can ask for services from any facility; customer and facility have a specific distance to each other, which is called coverage distance, thus every facility can service depending on the coverage requirement (Arabani and Farahani 2012). It was for the first time ever, in 1980, an alternated approach was presented to solve the problem of locating. It is a combined model including multi-aim TDCPs for every time limit. This approach was considered an alternate approach to solving facility location problems, inspired by the public sector need to locate emergency medical service (EMS) systems. $d_{i j t}$ is the shortest distance or time from node $i$ to node $j$ in period $t ; N_{i t}$ set of sites which can cover node $i$ in period $t ; h_{i t}$ demand weight on node $i$ in period $t ; P_{t}$ number of facilities operational in period $t \cdot x_{j t}$-if a facility is operating at site $j$ in period $t$, set $x_{j t}=1$, otherwise, set $x_{j t}=0 ; Y_{i t}$-if a facility is operating at node $i$ in period $t$, set $Y_{i t}=1$, otherwise, set $Y_{i t}=0$.

The mathematical model formulation is given by the following (Schiling 1980):

Maximize $\sum_{i} h_{i t} Y_{i t} \quad \forall t=1,2, \ldots, T$

Subject to:

$\sum_{j \in N_{i t}} X_{j t} \geq Y_{i t} \forall i, t$

$\sum_{j} X_{j t}=P_{t} \quad \forall t=1,2, \ldots, T$

$X_{j t} \geq X_{j, t-1} \quad \forall j, t=2, \ldots, T$

$X_{j t} \in\{0,1\} \quad \forall j, t=1,2, \ldots, T$

$Y_{i t} \in\{0,1\} \quad \forall i, t=1,2, \ldots, T$

This proposed model combines $T$ maximal covering problems; $Y_{i t}$ is equal to unity only when facilities are established at sites in the set $N_{i t}$ (Constraint 18). The number of operational facilities in period $t$ is $P_{t}$ (Constraint 19). Constraint (20) shows that when the center is opened it will be opened continuously to next periods too. Constraints (21) and (22) are decision variables.

To be specific first, DCPs were presented by Schiling (1980) and Gunawardane (1982) developed it in the way that penalties for opening or closing the facilities would reduce the amount of changes of relocation. Gendreau et al. (2001) studied the ambulances problem, and the goal was to maximize total demand covered and minimize travel cost. The model was also improved by Brotcorne et al. (2003) to probabilistic model which means ambulances operate as servers in a queueing system and cannot always answer a call. Rajagopalan et al. (2008) made a new covering model in dynamic problems to minimize the number of ambulances and their locations for the case which all of them are busy. Fazel Zarandi et al. (2013) developed a new method for DCPs.

\section{Alternative dynamic approaches}

\section{Stochastic and probabilistic dynamic facility location problems (SDFLPs \& PDFLPS)}

As it was mentioned in part 2, uncertainty occurs as input parameters for two reasons: (1) future conditions and (2) lack of knowledge (Owen and Daskin 1998 and Farahani 
and Hekmatfar 2009). As a whole, there are two approaches for optimization under an uncertain environment: stochastic programming (SP) and robust optimization (RO). In stochastic programming (SP) it is assumed that value of uncertain parameters are following the probability distributions with known parameters; however, in robust optimization it is assumed that no information about probability distributions is reachable except few data for the specification of intervals containing the uncertain values (Ghaffari-Nasab et al. 2015). Like most of stochastic models, it is possible to point out stochastic problems in scenario planning approach template (Arabani and Farahani 2012). In this model, $\mathrm{m}$ demand node, $\mathrm{n}$ candidate, location and $\mathrm{k}$ possible scenario exist (the parameter is considered under the scenario $k$ ) (Arabani and Farahani 2012).

Definition of parameters $h_{i k}, d_{i j k}, \hat{v}_{k}, q_{k}, R_{k}$ and decision variables $x_{j}$ and $y_{i j k}$ are like mentioned models in part 3.4.

$m_{k}$ is the large constant $m_{k} \geq R_{k} ; F$ available facilities. $z_{k}$-if the maximum regret is minimized under a set including scenario $k$, set $z_{k}=1$, otherwise, set $z_{k}=0$.

Now the stochastic programming model can be formulated as follows (Arabani and Farahani 2012):

Minimize $Z$

Subject to:

$$
\begin{aligned}
& \sum_{j=1}^{n} x_{j}=F \\
& \sum_{j=1}^{n} y_{i j k}=1 \quad \forall i, k \\
& y_{i j k}-x_{j} \leq 0 \quad \forall i, j, k \\
& R_{k}-\sum_{j=1}^{n} \sum_{i=1}^{m}\left(h_{i k} d_{i j k} y_{i j k}-\hat{v}_{k}\right)=0 \quad \forall k \\
& \sum_{k=1}^{K} q_{k} R_{k} \geq \alpha \\
& Z-R_{k}+m_{k}\left(1-z_{k}\right) \geq 0 \quad \forall k \\
& x_{j}=\{0,1\}, \quad y_{i j k}=\{0,1\}, \quad z_{k}=\{0,1\} \quad \forall i, j, k
\end{aligned}
$$

Objective function (23) minimizes the $\alpha$-reliable minimax regret. Constraint (24) represents the available number of facilities to be located. Constraint (25), demonstrated single allocation. If a facility is not located at node $j$, the demand of node $i$ cannot be satisfied under scenario $k$ (Constraint 26). Constraint (27) defined the regret attributed to scenario $k$. The least possible probability of selecting scenario must be $\alpha$ (Constraint 28). Constraint
(29) identified the maximum regrets. Constraint (30) is decision variable.

So, as an alternate to SDFLPs, location and relocation of facility is under a decision maker's control. The model is relocation policy that minimizes the expected present worth of all costs (Rosenthal et al. 1978).

Minimize $Z=E\left[\sum_{t-1}^{a}\left\{F\left(X_{t-1}, X_{t}\right)+G\left(X_{t}, A_{t}\right)\right\} B^{t-1}\right]$

$X_{t}$ is server location at time $t$, decision variable; $A_{t}$ customer location at time $t$, stochastic; $N$ known set of possible location for both $N:\{1, \ldots, n\} ; F$ known server relocation cost matrix, $n \times n$; $G$ known service cost matrix, $n \times n ; P$ known Markov transition matrix for customer location, and $n \times n ; B$ known discount factor (Rosenthal et al. 1978).

A discrete time process evolves as follows: (1) observes $\left(X_{t}, A_{t-1}\right)$ and chooses $X_{t}$, (2) relocating cost $f\left(X_{t}, A_{t-1}\right)$ is incurred, (3) chance probabilistic $A_{t}$ is realized and (4) service cost $g\left(X_{t}, A_{t}\right)$ is incurred (Rosenthal et al. 1978).

Probabilistic or stochastic demand parameter was first, presented by Henig and Gerchak (1986) and then Sherali (1991), Lee and Jeong (2009) and Zeballos et al. (2014) improved it in PDFLPs. Aghezzaf (2005), Romauch and Hartl (2005), Gabor and Van Ommeren (2006), Manzini and Gebennini (2008), Acar et al. (2009) and Wang (2014) studied the effect of demand parameter uncertainty in SDFLPs. Also Marufuzzaman and Eksioglu (2014) and Barkaoui and Boukhtouta (2015) developed probability of disruption and visit customer.

\section{Fuzzy dynamic facility location problems (FDFLPs)}

First, application of fuzzy approach in dynamic location problems (DLPs) will be classified into two categories: (1) selecting facilities location: to do this, there are three strategies being used: analytic hierarchy process (AHP), fuzzy TOPSIS, fuzzy information axiom; (2) location allocation problems: when using the fuzzy logic, in location allocation problems, Wen's model can be useful. Fuzzy parameters in the literature are demands, facility capacity and delivery cost (Arabani and Farahani 2012).

An electronic commerce (e-commerce) system has several subsets such as supplier $i \in I$, distribution centers $j \in J$ and customers $k \in K$ with multi-commodity $l \in L$ (Lau et al. 2010).

$H_{i l}$ is the unit supply cost of node i for the lth kind of commodities; $C_{i j l}$ unit transport cost from node $i$ to node $j$ for the lth kind of commodities; $U_{j l}$ unit inventory cost 
of node $j$ for the lth kind of commodities in the distribution period; $S_{j l}$ unit handling cost of node $j$ for the lth kind of commodities; $F_{j}(v)$ setup cost at node $j$ (Eq. 32); $F_{j 0}$ setup cost when $\mathrm{v}$ is less than critical capacity; $\tilde{B}_{j k}$ fuzzy delivery cost per unit from node $j$ to customer $k$ (Eq. 33); $B_{j}\left(I_{T}\right)$ cost of a tour through a customer $i \in I_{T}$ starting from node $j ; v$ capacity of node $j ; N_{j}$ and $M_{j}$ critical capacity and maximal capacity; $\tilde{A}_{i l}$ fuzzy supply capacity of supplier $i$ for the lth kind of commodities in the plan period; $\tilde{D}_{k l}$ fuzzy demand of customer $k$ for the lth kind of commodities in the plan period; $m$ number of transport periods in the plan period; $n$ number of distribution periods in the transport period; $x_{i j l}$ number of the $l$ th kind of commodities transported from supplier $\mathrm{i}$ to distribution center $j$ in each transport period; $P$ maximum number of selected distribution centers; $Q\left(I_{T}\right)$ total commodity weight units of the cluster; $d_{j k}$ distance between distribution center $j$ and customer $k ; S_{\max }$ maximum tour length of vehicles; $E_{j 0}$ coefficient of setup cost; $\phi$ coefficient of economies of scale, $\phi \in(0,1) ; r$ scale coefficient of handling cost; $w_{l}$ unit bulk coefficient of the $l$ th kind of commodities; $q_{l}$ unit weight coefficient of the $l$ th kind of commodities $l \in L$ (Lau et al. 2010).

$F_{j}(v)=\left\{\begin{array}{l}F_{j 0}+E_{j 0}\left(v-N_{j}\right)^{\phi} \quad N_{j}<v \leq M_{j} \\ F_{j 0}, \quad 0<v \leq N_{j} \\ 0, \quad v=0\end{array}\right.$

$B_{j k}=\left\{\begin{aligned} \infty, & \text { if } 2 d_{j k}>S_{\max } \\ \frac{B_{j}\left(I_{T}\right)}{Q\left(I_{T}\right)}, & \text { otherwise }\end{aligned}\right.$

$y_{j}$-if distribution center $j$ is selected, set $y_{j}=1$, otherwise, set $y_{j}=0 ; z_{j k}$-if customer $k$ is delivered by distribution center $j$, set $z_{j k}=1$, otherwise, set $z_{j k}=0$.

Now the fuzzy programming model for location of distribution center can be formulated as follows (Lau et al. 2010):

$$
\begin{array}{r}
\text { Minimize } \quad m \sum_{i \in I} \sum_{l \in L} H_{i l} \sum_{j \in J} x_{i j l}+m \sum_{i \in I} \sum_{l \in L} \sum_{j \in J} C_{i j l} x_{i j l} \\
+\sum_{j \in J} F_{j}(v) \sum_{i \in I} \sum_{l \in L} w_{l} x_{i j l}+m \sum_{i \in I} \sum_{l \in L} \sum_{j \in J} \sum_{\tau=1}^{n} U_{j l} \frac{x_{i j l}}{n} \tau \\
+m \sum_{i \in I} \sum_{l \in L} \sum_{j \in J} S_{j l} x_{i j l}+\sum_{j \in J} \sum_{k \in K} \tilde{B}_{j k} z_{j k} \sum_{l \in L} q_{l} \tilde{D}_{k l}
\end{array}
$$

subject to:

$$
\begin{array}{ll}
m \sum_{j \in J} x_{i j l} \leq \tilde{A}_{i l} & \forall i \in I, l \in L \\
m \sum_{i \in I} x_{i j l}=\sum_{k \in K} \tilde{D}_{k l} z_{j k} & \forall j \in J, l \in L
\end{array}
$$

$$
\begin{array}{ll}
\sum_{i \in I} \sum_{l \in L} w_{l} x_{i j l} \leq M_{j} y_{j} & \forall j \in J \\
\sum_{j \in J} y_{j} \leq P & \\
\sum_{j \in J} z_{j k}=1 & \forall k \in K \\
r y_{j-} \sum_{k \in K} z_{j k} \geq 0 & \\
x_{i j l} \geq 0 & \\
y_{j} \in\{0,1\} & \\
z_{j k} \in\{0,1\} \quad \forall i \in I, & \forall j \in J, \quad \forall l \in L
\end{array}
$$

Fuzzy constraints (35) and (36) assure that all commodities transported from suppliers are not more than its capacity and there should be balance between every input and output center. Constraints (37), (38) and (39) show the maximum capacity and number of every distribution center and single allocation. Every selected distribution center services several customers (40). Constraint (41) is decision variable.

Lau et al. (2010) was the first one who presented FDFLPs with fuzzy parameters of demand, facility capacity and delivery cost in an e-commerce network and then two fuzzy parameters, demand and facility capacity were developed by Taghipourian et al. (2012) in dynamic Hub facility location problems. Fuzzy demand was studied in two articles: dairy facility location problem by Jouzdani et al. (2013) and location-routing problem by Nadizadeh and Hosseini Nasab (2015).

\section{Dynamic hub facility location problems (DHFLPs)}

In 2010, dynamic hub facility location problems were first studied to minimize fixed cost, transportation and routing costs. Set of potential hub location $i, j \in H$, set of subsets of $\mathrm{H}$ including one or two hubs $e \in E$, set of commodity in time horizon $t \in T$, all are reachable.

$W_{k}^{t}$ is the amount of commodity $k$ to be transported at period $t ; f_{i}^{t}$ fixed cost of opening a hub at node $i$ at the beginning of period $t ; g_{i}^{t}$ cost of operating a hub at node $i$ in period $t ; q_{i}^{t}$ recovery gain associated with closing a hub located at node $\mathrm{i}$ in period $t ; \hat{F}_{i j k}^{t}$ transportation cost or routing commodity $k, \hat{F}_{i j k}^{t}=W_{k}^{t}\left(d_{o(k) i}^{t}+\alpha d_{i j}^{t}+d_{j d(k)}^{t}\right)$; $F_{e k}^{t} \quad$ undirected transportation cost $F_{e k}^{t} \in \min \left\{\hat{F}_{i j k}^{t}\right.$, $\left.\hat{F}_{j i k}^{t}\right\} ; \alpha$ discount factor between two hub nodes; $o(k), d(k)$ origin and destination nodes of commodity $k$.

$x_{e k}^{t}$-if commodity $k$ at period $t$ uses hub edge $e$, set $x_{e k}^{t}=1$, otherwise, set $x_{e k}^{t}=0 ; z_{i}^{t}$-if a hub facility is located at node $i$ in period $t$, set $z_{i}^{t}=1$, otherwise, set $z_{i}^{t}=0$. 
The mathematical model formulation is given by the following (Contreras et al. 2010):

$$
\begin{aligned}
\text { Minimize } & \sum_{i \in H} \sum_{t \in T} f_{i}^{t}\left(1-z_{i}^{t-1}\right) z_{i}^{t}+\sum_{i \in H} \sum_{t \in T} g_{i}^{t}(1-z) z_{i}^{t} \\
& -\sum_{i \in H} \sum_{t \in T} q_{i}^{t}\left(1-z_{i}^{t}\right) z_{i}^{t-1}+\sum_{e \in E} \sum_{k \in K} \sum_{t \in T} F_{e k}^{t} x_{e k}^{t}
\end{aligned}
$$

subject to:

$\sum_{e \in E} x_{e k}^{t}=1$

$$
\forall k \in K, t \in T
$$

$\sum_{\{e \in E: i \in e\}} x_{e k}^{t} \leq z_{i}^{t} \quad \forall i \in H, k \in K, t \in T$

$x_{e k}^{t} \geq 0$

$$
\forall e \in E, k \in K, t \in T
$$

$z_{i}^{t} \in\{0,1\}$

$$
\forall i \in H, t \in T
$$

Constraint (43) assures each commodity from origindestination path has single allocation in period $t$. Constraint (44) also emphasizes that commodities route has to pass hub nodes. Constraints (45) and (46) show decision variables.

Specifically, first DHFLPs were presented by Contreras et al. (2010) and then, Terymourian et al. (2011) studied dynamic virtual hub location problem in airline networks with adverse weather conditions. Also it was developed by Taghipourian et al. (2012) with fuzzy parameters. Correia et al. (2012) investigated existence of exogenous budget available at the beginning of time period for installing and removing hubs. Marufuzzaman and Eksioglu (2014) developed an economic model, which is based on an efficient hub network, to hedge against fossil fuels fluctuations and natural disasters. Dynamic hub facility location model that has logistic servers was presented by Horhammer (2014). Horhammer (2014) minimized total costs of collection, distribution, operational, fixed, closing and changing facilities capacity. Bashiri and Hamidian (2015) developed p-median hub location problem with multiple allocations and Gelareh et al. (2015) expanded dynamic location allocation hub network with limited budget.

\section{Dynamic model with continuous time (DMCT)}

Dynamic model with continuous time are most appropriate for strategic planning to find the best location and relocation time to serve and expanding demand with minimizing the transportation and relocation costs. $S$ is a service region (Campbell 1990).

$K(t)$ is the number of terminals in the system at time $t$; $X_{j}(t)$ location of terminal $j$ at time $t ; M(t)$ the cumulative number of terminal relocations at time $t ; \rho(x, t)$ demand density at location $x$ at time $t$; $q$ discount rate (proportion of value per unit time); $r$ the total discounted relocation cost; $D(x, X(t))$ average transportation cost per shipment at time $t$ originating at location $x$.

Objective function and constraints of the problem should be as it is mentioned below (Campbell 1990):

$$
\begin{aligned}
\text { Minimize } C(X(t))= & \int_{t_{0}}^{\infty} K(t) e^{-q t} d t+\int_{t_{0}}^{\infty} M(t) r e^{-q t} \mathrm{~d} t \\
& +\int_{t_{0}}^{\infty}\left[\int_{s} \rho(x, t) D(x, X(t)) d x\right] e^{-q t} \mathrm{~d} t
\end{aligned}
$$

\section{Solution approaches and algorithms for dynamic location problems}

A large variety of algorithm methods are proposed to solve dynamic location problems (DLPs). Solution methods can be divided into two general categories: (1) exact methods, (2) heuristic and metaheuristic. Exact algorithm of linear programming such as branch-andbound solution technique is a method in which at every node of the branching tree are obtained lower and upper bounds (Land and Doig 1960), Lagrangian relaxation (LR) method which is used for solving large-scale combinatorial optimization problems (Fisher 1981), Benders decomposition algorithm allows to solve a linear programming problem with complicating variables using Benders cut (Benders 1962), dynamic programming (DP) breaking the complex problems down into a collection of simpler sub-problems (Bellman 1975), etc. These exact methods more common and usually used to solve the small and medium size, but these solution methods are not profitable to solve the larger size and complex dimensional problems. Nowadays, for solving the complex dynamic location problem, which are called NP-hard problems, heuristic and metaheuristic approaches such as genetic algorithm (GA) (Holland 1992), tabu search (TS) (Glover 1986) and simulated annealing (SA) (Kirkpatrick et al. 1983) or combination of them are developed. These methods give the near-optimum solution and are applied for the time that obtaining the optimum solution is not possible.

\section{Application of exact solution method in dynamic location problems}

Classical exact algorithms such as integer programming (IP) and dynamic programming (DP) used since the mid1960s to solve dynamic location problems when the size is 
Table 3 Exact solution algorithm in DLPs

\begin{tabular}{|c|c|c|}
\hline Author's (year) & Solution technique & Description \\
\hline \multicolumn{3}{|l|}{ Exact (general method) } \\
\hline Ballou (1968) & Dynamic Programming (DP) & - \\
\hline Scott $(1971)$ & Dynamic Programming (DP) & - \\
\hline Tapiero (1971) & Lagrangian Relaxation & - \\
\hline Wesolowsky (1973) & Dynamic Programming (DP) & - \\
\hline Wesolowsky and Truscott (1975) & Dynamic Programming (DP) and Integer Programming (IP) & - \\
\hline Sweeney and Tatham (1976) & Dynamic Programming (DP) and Bender's Decomposition & $\begin{array}{l}\text { Solving IP with Benders' } \\
\text { decomposition, then using DP } \\
\text { to determine an optimal } \\
\text { location and relocation strategy }\end{array}$ \\
\hline Roodman and Shwarz (1977) & Branch-and-bound & $\begin{array}{l}\text { Branch-and-bound procedure is } \\
\text { improved two new lower } \\
\text { bounds }\end{array}$ \\
\hline Gunawardane (1982) & Branch-and-bound & - \\
\hline Kelly and Marucheck (1984) & Bender's decomposition & - \\
\hline Henig and Gerchak (1986) & Dynamic programming (DP) & - \\
\hline Sherali (1991) & Exact & - \\
\hline Shulman (1991) & Dynamic programming (DP) and lagrangian relaxation (LR) & $\begin{array}{l}\text { DP algorithm for solving sub } \\
\text { problem and using LR of the } \\
\text { capacity constraints }\end{array}$ \\
\hline Melachrinoudis et al. (1995) & Weighted method & - \\
\hline Hormozi and Khumawala (1996) & Dynamic programming (DP) & $\begin{array}{l}\text { Using a mixed integer } \\
\text { programming model and a DP } \\
\text { approach the problem is } \\
\text { subdivided into smaller simpler } \\
\text { problems }\end{array}$ \\
\hline Canel and Khumawala (1997) & Branch-and-bound & - \\
\hline Current et al. (1997) & Exact & $\begin{array}{l}\text { Solved expected opportunity loss } \\
\text { (EOL) }\end{array}$ \\
\hline Averbakh et al. (1998) & Dynamic programming (DP) & - \\
\hline Min and Melachrinoudis (1999) & Analytic hierarchy process (AHP) & - \\
\hline Hinojosa et al. (2000) & Branch-and-bound and Lagrangian relaxation (LR) and heuristic algorithm & $\begin{array}{l}\text { Develop an ascent procedure to } \\
\text { generate a good solution for the } \\
\text { relaxed problem }\end{array}$ \\
\hline Melachrinoudis and Min (2000) & Weighted method & - \\
\hline Alonso-Ayuso et al. (2003) & Branch-and-fix coordination (BFC) algorithm & - \\
\hline Brotcorne et al. (2003) & Exact & - \\
\hline Gue (2003) & Exact & - \\
\hline Ambrosino and Scutella (2005) & Exact & - \\
\hline Melo et al. (2005) & Branch-and-bound & - \\
\hline Miller et al. (2007) & Stackelberg-nash-cournot competitive & - \\
\hline Behmardi and Lee (2008) & Branch-and-bound & - \\
\hline Gourdin and Klopfenstein (2008) & Exact & - \\
\hline Hinojosa et al. (2008) & $\begin{array}{l}\text { Branch-and-Bound and Lagrangian Relaxation (LR) and Heuristic } \\
\text { Algorithm }\end{array}$ & $\begin{array}{l}\text { Develop an ascent procedure to } \\
\text { generate a good solution for the } \\
\text { relaxed problem }\end{array}$ \\
\hline Manzini and Gebennini (2008) & Exact & - \\
\hline Thanh et al. (2008) & Branch-and-Bound & - \\
\hline Acar et al. (2009) & Exact & Hybrid solution methodology \\
\hline Albareda-Sambola et al. (2009) & Lagrangian Relaxation (LR) & - \\
\hline Farahani et al. (2009) & Dynamic Programming (DP) & - \\
\hline Gebennini et al. (2009) & Exact & - \\
\hline Lee and Jeong (2009) & Exact & Regression approximation \\
\hline Mahar et al. (2009) & Branch-and-Bound and Dynamic Programming & - \\
\hline Naraharisetti and Karimi (2010) & Exact & - \\
\hline Sepehri (2011) & Exact & - \\
\hline
\end{tabular}


Table 3 continued

\begin{tabular}{|c|c|c|}
\hline Author's (year) & Solution technique & Description \\
\hline Benneyan et al. (2012) & Exact & - \\
\hline Carle et al. (2012) & Exact & - \\
\hline Correia et al. (2013) & Exact & - \\
\hline Ghaderi and Jabalameli (2013) & Branch-and-Bound & - \\
\hline Cucek et al. (2014) & Exact & - \\
\hline Horhammer (2014) & Exact & - \\
\hline Marufuzzaman and Eksioglu (2014) & Bender's Decomposition & - \\
\hline Zeballos et al. (2014) & Exact & Clustering the customers \\
\hline Archetti et al. (2015) & Branch-and-Cut & - \\
\hline Bashiri and Hamidian (2015) & Exact & - \\
\hline Dayarian et al. (2015) & Dynamic programming (DP), column generation and branch-and-price & - \\
\hline Gelareh et al. (2015) & Bender's Decomposition & - \\
\hline \multicolumn{3}{|l|}{ Exact (specific method) } \\
\hline Drezner and Wesolowsky (1991) & Branch-and-Bound and Heuristic algorithm & - \\
\hline Chardaire et al. (1996) & Lagrangian Relaxation and Heuristic & $\begin{array}{l}\text { Methods for generating heuristic } \\
\text { solutions (by simulated } \\
\text { annealing) and good lower } \\
\text { bounds (by LR) }\end{array}$ \\
\hline $\begin{array}{l}\text { Saldanha-da-Gama and Captivo } \\
\text { (1998) }\end{array}$ & $\begin{array}{l}\text { Dynamic Programming (DP) and Branch-and-Bound and Heuristic } \\
\text { Algorithm }\end{array}$ & $\begin{array}{l}\text { DP was used for smaller } \\
\text { problems and branch-and- } \\
\text { Bound procedure in solving } \\
\text { large instances }\end{array}$ \\
\hline Canel et al. (2001) & Branch-and-Bound and Dynamic Programming (DP) & $\begin{array}{l}\text { Algorithm is segmented into } \\
\text { three phases: Phase I, is the } \\
\text { dynamic cycle. Phase II, } \\
\text { branch-and-bound (list of } \\
\text { candidate static facility } \\
\text { configurations). Phase III, DP } \\
\text { (optimal solution) }\end{array}$ \\
\hline Averbakh et al. (2007) & Dynamic Programming (DP) & - \\
\hline Abravaya and Brend (2009) & Exact & Specific algorithm \\
\hline Contreras et al. (2010) & Branch-and-Bound and Lagrangian Relaxation (LR) & $\begin{array}{l}\text { LR can be incorporated in a } \\
\text { branch-and-bound algorithm in } \\
\text { order to obtain the optimal } \\
\text { solution }\end{array}$ \\
\hline Torres-Soto and Uster (2011) & $\begin{array}{l}\text { Lagrangian Relaxation (LR) and Bender's Decomposition and Branch-and- } \\
\text { cut }\end{array}$ & - \\
\hline
\end{tabular}

traceable (e.g., small and medium size). In Table 3, all the related researches since 1986 till now are studied individually and summarized based on the exact solution methods which have been used to solve the dynamic location models.

\section{Application of heuristic, uncertain method and meta-heuristic solution method in dynamic location problems}

The first heuristic approach for dynamic location problems was developed at the end of 1960s. As the solutions being used for small and medium size were not efficient for larger size heuristic, meta-heuristic approaches such as genetic algorithm (GA), tabu search (TS), and simulated annealing (SA) or combination approaches were used. All the published researches since 1986 to now have been studied and classified in Table 4 based on their heuristic and metaheuristic and uncertain methods.

More than $56 \%$ of published articles listed in Tables 3 and 4 have utilized exact solution methods and less than $44 \%$ heuristic and metaheuristic methods to solve dynamic location problems. For instance, about $21 \%$ of articles have utilized branch-and-bound methods, about $24 \%$ dynamic programming (DP) methods, about $12 \%$ Lagrangian relaxation (LR) and about $9 \%$ Bender's decomposition methods.

In recent years, solution methods such as fuzzy programming, branch-and-cut, branch-and-price, branch-andfix, fuzzy chance constraint programming, robust optimization or a combination of exact method and heuristic or metaheuristic have been used. 
Table 4 Heuristic, uncertain method and meta-heuristic solution algorithm in DLPs

\begin{tabular}{|c|c|c|}
\hline Author's (year) & Solution technique & Description \\
\hline \multicolumn{3}{|l|}{ Heuristic } \\
\hline Rosenthal et al. (1978) & Heuristic iterative algorithm & - \\
\hline Schilling (1980) & Heuristic algorithm and weighted method & $\begin{array}{l}\text { A heuristic algorithm was developed and } \\
\text { appended to the weighting method }\end{array}$ \\
\hline Erlenkotter (1981) & Heuristic algorithm & $\begin{array}{l}\text { Combining heuristic approaches such as SLOT, } \\
\text { the earliest heuristic for the dynamic location } \\
\text { problem, Incomplete dynamic programming } \\
\text { (IDP-MAC) Minimum annual cost (MAC) }\end{array}$ \\
\hline VanRoy and Erlenkotter (1982) & $\begin{array}{l}\text { Heuristic dual ascent algorithm [branch-and-bound } \\
\text { and Lagrangian relaxation (LR)] }\end{array}$ & $\begin{array}{l}\text { A branch and bound procedure with lower } \\
\text { bounds obtained through solving LR with a } \\
\text { heuristic dual ascent method was proposed }\end{array}$ \\
\hline $\begin{array}{l}\text { Frantzeskakis and Watson-Gandy } \\
\text { (1989) }\end{array}$ & $\begin{array}{l}\text { Heuristic, branch-and-bound and dynamic } \\
\text { programming (DP) }\end{array}$ & $\begin{array}{l}\text { Using both dynamic programming and a branch } \\
\text { and bound approach using state space } \\
\text { relaxation }\end{array}$ \\
\hline Campbell (1990) & Heuristic & Using three strategies \\
\hline Bastian and Volkmer (1992) & Heuristic algorithm & Policy tree algorithm \\
\hline Daskin et al. (1992) & Heuristic dual ascent algorithm & Using the dual ascent algorithm \\
\hline $\begin{array}{l}\text { Galvao and Santibanez-Gonzalez } \\
\text { (1992) }\end{array}$ & $\begin{array}{l}\text { Lagrangian heuristic algorithm and Lagrangian } \\
\text { relaxation method }\end{array}$ & - \\
\hline Andreatta and Mason (1994) & Heuristic algorithm & Policy tree algorithm \\
\hline Romeijn and Morales (2004) & Greedy heuristic & - \\
\hline Romauch and Hartl (2005) & $\begin{array}{l}\text { Stochastic dynamic programming and heuristic } \\
\text { algorithm [Monte Carlo and Sample Average } \\
\text { Approximation (SAA)] }\end{array}$ & $\begin{array}{l}\text { Comparison of the heuristic results and the exact } \\
\text { solution method }\end{array}$ \\
\hline Dias et al. (2006) & Primal Dual Heuristic & - \\
\hline Gabor and Ommeren (2006) & Approximation Algorithms & - \\
\hline Dias et al. (2007a) & Primal dual Heuristic and branch-and-bound & - \\
\hline Dias et al. (2007b) & Primal dual heuristic & - \\
\hline Dias et al. (2008b) & Primal dual heuristic & - \\
\hline Dias et al. (2008c) & Primal dual heuristic & - \\
\hline Correia et al. (2012) & Heuristic approach & Local search \\
\hline Sha and Huang (2012) & Heuristic algorithm and lagrangian relaxation (LR) & Heuristic algorithm based on LR \\
\hline \multicolumn{3}{|l|}{ Uncertain method } \\
\hline Aghezzaf (2005) & $\begin{array}{l}\text { Robust optimization (RO) and decomposition } \\
\text { algorithm, lagrangian relaxation (LR) }\end{array}$ & $\begin{array}{l}\text { A robust optimization model was developed and } \\
\text { solving LR decomposition algorithm with two } \\
\text { separate sub-problems }\end{array}$ \\
\hline Lau et al. (2010) & Fuzzy chance constraint programming & Credibility based fuzzy \\
\hline Taghipourian et al. (2012) & Fuzzy programming approach & - \\
\hline Jauzdani et al. (2013) & Fuzzy programming approach & - \\
\hline $\begin{array}{l}\text { Nadizadeh and Hosseini Nasab } \\
\text { (2015) }\end{array}$ & $\begin{array}{l}\text { Hybrid heuristic algorithm (HHA) and fuzzy } \\
\text { credibility theory }\end{array}$ & $\begin{array}{l}\text { Using an accelerated bender's decomposition } \\
\text { algorithm and credibility theory }\end{array}$ \\
\hline \multicolumn{3}{|l|}{ Metaheuristic } \\
\hline Ghaderi and Jabalameli (2013) & $\begin{array}{l}\text { Branch and bound, hybrid greedy heuristic and fix- } \\
\text { and-optimize heuristic and hybrid simulated } \\
\text { annealing (SA) }\end{array}$ & $\begin{array}{l}\text { Fix-and-optimize heuristic based on simulated } \\
\text { annealing (SA) }\end{array}$ \\
\hline Jawahar and Balaji (2012) & Genetic algorithm (GA) and heuristic algorithm & - \\
\hline Bozkaya et al. (2010) & Genetic algorithm (GA) and tabu search (TS) & $\begin{array}{l}\text { Genetic algorithm principles to decide which } \\
\text { locations to open, and uses tabu search (TS) } \\
\text { algorithm to calculate vehicle routing costs }\end{array}$ \\
\hline Wang et al. (2011) & $\begin{array}{l}\text { Genetic Algorithm with linear programming (GA- } \\
\text { LP) and genetic algorithm with greedy heuristics } \\
\text { (GA-Greedy) }\end{array}$ & - \\
\hline
\end{tabular}


Table 4 continued

\begin{tabular}{|c|c|c|}
\hline Author's (year) & Solution technique & Description \\
\hline Antunes and Peeters (2000) & Heuristic and simulated annealing (SA) & $\begin{array}{l}\text { Used two fast, well-known local search } \\
\text { heuristics }\end{array}$ \\
\hline Antunes and Peeters (2001) & Heuristic and simulated annealing (SA) & $\begin{array}{l}\text { Used two fast, well-known local search } \\
\text { heuristics }\end{array}$ \\
\hline Barkaoui and Boukhtonta (2015) & Hybrid genetic algorithm (GA) & - \\
\hline Teymourian et al. (2011) & Hybrid simulated annealing & $\begin{array}{l}\text { Six new neighborhood structures for our } \\
\text { proposed metaheuristic approach }\end{array}$ \\
\hline Fattahi et al. (2015) & $\begin{array}{l}\text { Linear relaxation heuristic and simulated annealing } \\
\text { (SA) }\end{array}$ & $\begin{array}{l}\text { Simulating annealing (SA) algorithm and several } \\
\text { developed linear } \\
\text { relaxation-based heuristics }\end{array}$ \\
\hline Dias et al. (2008a) & Memetic algorithm and heuristic algorithm & Used local search \\
\hline Gelareh et al. (2015) & Metaheuristic algorithm & - \\
\hline Bashiri and Hamidian (2015) & Simulated annealing (SA) & - \\
\hline Fazel Zarandi et al. (2013) & Simulated annealing (SA) & Used neighborhood search structure (NSS) \\
\hline Syam (2002) & $\begin{array}{l}\text { Simulated annealing (SA) and Lagrangian relaxation } \\
\text { (LR) }\end{array}$ & $\begin{array}{l}\text { Simulated annealing approach uses LR to } \\
\text { address the secondary issue and annealing to } \\
\text { determine optimal sites }\end{array}$ \\
\hline Gen and Syarif (2005) & spanning tree based genetic Algorithm (hst-GA) & $\begin{array}{l}\text { Fuzzy logic controller (FLC) concept for auto- } \\
\text { tuning the GA parameters }\end{array}$ \\
\hline Dayarian et al. (2015) & Tabu Search (TS) & - \\
\hline Gendreau et al. (2001) & Tabu Search (TS) and Heuristic Algorithm & A sequential tabu search heuristic \\
\hline Rajagopalan et al. (2008) & Tabu Search (TS) and Heuristic Algorithm & A reactive tabu search algorithm \\
\hline $\begin{array}{l}\text { De Armas and Melián-Batista } \\
\text { (2015) }\end{array}$ & Variable Neighborhood Search (VNS) & - \\
\hline Miskovic et al. (2015) & Variable Neighborhood Search (VNS) & - \\
\hline Wen et al. (2010) & Variable Neighborhood Search (VNS) & Three phase heuristic (TPH) \\
\hline
\end{tabular}

\section{Applications of solution method, application fields and real-life case studies}

In this section, we study the literature of dynamic location problems (DLPs) pursuant to application basis as well as the relevant case studies. Table 5 categorizes the literature of DLPs in terms of its applications due to the solution methods, industrial context and fields. In addition, the applications and description of real-world case studies are classified in Table 6. According to Tables 5 and 6, the productiondistribution systems are studied more than some other categories. From Tables 5 and 6 it can also be recognized that two subjects of competition problems and hub location problems are more attended in the recent years. $75 \%$ of dynamic location problems on real-world case studies were published after 2000 (in the last 15 years).

\section{Conclusions and future trends}

In this review paper, it has been attempted to prepare a trend of dynamic location problems literature and other relevant concepts, all the published papers are studied and classified according to their properties of problem and parameters. Objective functions, optimization models, parameters, constraints, techniques and solution method based on two categories: (1) exact algorithm; (2) heuristic and metaheuristic algorithms have been analyzed and categorized for all the published papers.

Moreover, there is a classification of dynamic location articles based on application and case studies (industrial field), that are gathered and classified in this review paper. Some of possible trend for future works, based on gapes of recent literature are presented to conduct future studies on dynamic location problems.

Our analysis on the characteristics of models, solution methods and applicability of published papers suggests the ways for future research in Dynamic location problems (DLPs).

To the future research, the implementation of variety of services (hierarchical network), reliability, sustainability, planning for global logistics and relief management in crisis, waiting time for services (queuing theory) and risk of facility disruption need to be taken into account as new recent trends and contributions and further study in DLPs. Specific conclusion emerging from the present study have been discussed comprehensively as follows: 
Table 5 Applications of solution method and application fields for DLPs

\begin{tabular}{|c|c|c|c|}
\hline $\begin{array}{l}\text { Applications of } \\
\text { location problem }\end{array}$ & Author's (year) & Description fields of applications & Solution technique \\
\hline \multirow{2}{*}{$\begin{array}{l}\text { Competitive } \\
\text { systems }\end{array}$} & Miller et al. (2007) & Competitive plant location problem & Stackelberg-Nash-Cournot Competitive \\
\hline & Bozkaya et al. (2010) & $\begin{array}{l}\text { Competitive multi-facility location-routing } \\
\text { problem }\end{array}$ & Genetic Algorithm (GA) and Tabu Search (TS) \\
\hline \multirow{32}{*}{$\begin{array}{l}\text { Distribution } \\
\text { systems }\end{array}$} & Scott (1971) & Location-allocation problem & Dynamic Programming (DP) \\
\hline & Tapiero (1971) & Transportation location-allocation problems & Lagrangian Relaxation \\
\hline & Wesolowsky (1973) & Location-allocation problem & Dynamic Programming (DP) \\
\hline & $\begin{array}{l}\text { Wesolowsky and } \\
\text { Truscott (1975) }\end{array}$ & Location-allocation problem & $\begin{array}{l}\text { Dynamic Programming (DP) and Integer } \\
\text { Programming (IP) }\end{array}$ \\
\hline & $\begin{array}{l}\text { Roodman and Shwarz } \\
\text { (1977) }\end{array}$ & $\begin{array}{l}\text { Problem of withdrawing inventory and } \\
\text { service facilities }\end{array}$ & Branch-and-Bound \\
\hline & Rosenthal et al. (1978) & Dynamic relocation decision & Heuristic Iterative Algorithm \\
\hline & Erlenkotter (1981) & Plant location problem & Heuristic Algorithm \\
\hline & Gunawardane (1982) & Public facility location & Branch-and-Bound \\
\hline & $\begin{array}{l}\text { Frantzeskakis and } \\
\text { Watson-Gandy (1989) }\end{array}$ & $\begin{array}{l}\text { Potential depot location (location-allocation } \\
\text { problem) }\end{array}$ & $\begin{array}{l}\text { Heuristic, Branch-and-Bound and Dynamic } \\
\text { Programming (DP) }\end{array}$ \\
\hline & Campbell (1990) & Locating transportation terminals & Heuristic \\
\hline & $\begin{array}{l}\text { Drezner and } \\
\text { Wesolowsky (1991) }\end{array}$ & Single facility location problem & Branch-and-Bound and Heuristic algorithm \\
\hline & Sherali (1991) & Location-allocation problem & Exact \\
\hline & Shulman (1991) & Plant location problem & $\begin{array}{l}\text { Dynamic Programming (DP) and Lagrangian } \\
\text { Relaxation (LR) }\end{array}$ \\
\hline & $\begin{array}{l}\text { Bastian and Volkmer } \\
\text { (1992) }\end{array}$ & Single facilities location/relocation problem & Heuristic Algorithm \\
\hline & Daskin et al. (1992) & Location-allocation problem & Heuristic Dual Ascent Algorithm \\
\hline & $\begin{array}{l}\text { Galvao and Santibanez- } \\
\text { Gonzalez (1992) }\end{array}$ & $\begin{array}{l}\text { Potential facility (p-median location } \\
\text { problem) }\end{array}$ & $\begin{array}{l}\text { Lagrangean Heuristic Algorithm and } \\
\text { Lagrangian Relaxation Method }\end{array}$ \\
\hline & $\begin{array}{l}\text { Andreatta and Mason } \\
\text { (1994) }\end{array}$ & Single facilities location/relocation problem & Heuristic Algorithm \\
\hline & $\begin{array}{l}\text { Hormozi and } \\
\text { Khumawala (1996) }\end{array}$ & - & Dynamic Programming (DP) \\
\hline & $\begin{array}{l}\text { Canel and Khumawala } \\
\text { (1997) }\end{array}$ & International facility location & Branch-and-Bound \\
\hline & Current et al. (1997) & $\begin{array}{l}\text { Facility location with decision analysis } \\
\text { approach }\end{array}$ & Exact \\
\hline & Averbakh et al. (1998) & Plant location problem & Dynamic programming (DP) \\
\hline & $\begin{array}{l}\text { Saldanha-da-Gama and } \\
\text { Captivo (1998) }\end{array}$ & Location-allocation problem & $\begin{array}{l}\text { Dynamic Programming (DP) and Branch-and- } \\
\text { Bound and Heuristic Algorithm }\end{array}$ \\
\hline & Canel et al. (2001) & Multi-stage facility location problem & $\begin{array}{l}\text { Branch-and-Bound and Dynamic } \\
\text { Programming (DP) }\end{array}$ \\
\hline & Syam (2002) & Traditional facility location models & $\begin{array}{l}\text { Simulated Annealing (SA) and Lagrangian } \\
\text { Relaxation (LR) }\end{array}$ \\
\hline & Gue (2003) & Military logistics and location-inventory & Exact \\
\hline & $\begin{array}{l}\text { Ambrosino and Scutella } \\
\text { (2005) }\end{array}$ & $\begin{array}{l}\text { Location routing with warehousing, } \\
\text { transportation and inventory decisions }\end{array}$ & Exact \\
\hline & Dias et al. (2006) & - & Primal Dual Heuristic \\
\hline & $\begin{array}{l}\text { Gabor and Ommeren } \\
\text { (2006) }\end{array}$ & Inventory control & Approximation Algorithms \\
\hline & Averbakh et al. (2007) & Location-allocation problem & Dynamic Programming (DP) \\
\hline & Dias et al. (2007a) & - & Primal Dual Heuristic and Branch-and-Bound \\
\hline & Dias et al. (2007b) & - & Primal Dual Heuristic \\
\hline & Dias et al. (2008a) & - & Memetic Algorithm and Heuristic Algorithm \\
\hline
\end{tabular}


Table 5 continued

\begin{tabular}{|c|c|c|c|}
\hline $\begin{array}{l}\text { Applications of } \\
\text { location problem }\end{array}$ & Author's (year) & $\begin{array}{l}\text { Description fields of } \\
\text { applications }\end{array}$ & Solution technique \\
\hline & Dias et al. (2008b) & - & Primal Dual Heuristic \\
\hline & Dias et al. (2008c) & - & Primal Dual Heuristic \\
\hline & $\begin{array}{l}\text { Abravaya and Brend } \\
\text { (2009) }\end{array}$ & - & Exact \\
\hline & $\begin{array}{l}\text { Albareda-Sambola } \\
\text { et al. (2009) }\end{array}$ & $\begin{array}{l}\text { Incremental services facility } \\
\text { location problem }\end{array}$ & Lagrangian Relaxation (LR) \\
\hline & $\begin{array}{l}\text { Farahani et al. } \\
\text { (2009) }\end{array}$ & $\begin{array}{l}\text { Single facility location } \\
\text { (highway policy } \\
\text { department) }\end{array}$ & Dynamic Programming (DP) \\
\hline & $\begin{array}{l}\text { Lee and Jeong } \\
\text { (2009) }\end{array}$ & Inventory system & Exact \\
\hline & Lau et al. (2010) & - & Fuzzy Chance Constraint Programming \\
\hline & Wen et al. (2010) & $\begin{array}{l}\text { Vehicle routing problem } \\
\text { (bioenergy and agriculture) }\end{array}$ & Variable Neighborhood Search (VNS) \\
\hline & $\begin{array}{l}\text { Torres-Soto and } \\
\text { Uster (2011) }\end{array}$ & Logistic distribution system & $\begin{array}{l}\text { Lagrangian Relaxation (LR) and Bender's Decomposition and } \\
\text { Branch-and-cut }\end{array}$ \\
\hline & Wang et al. (2011) & Location-allocation problem & $\begin{array}{l}\text { Genetic Algorithm with Linear Programming (GA-LP) and } \\
\text { Genetic Algorithm with Greedy Heuristics (GA-Greedy) }\end{array}$ \\
\hline & $\begin{array}{l}\text { Jawahar and Balaji } \\
\text { (2012) }\end{array}$ & $\begin{array}{l}\text { Fixed charge distribution } \\
\text { problem }\end{array}$ & Genetic Algorithm (GA) and Heuristic Algorithm \\
\hline & $\begin{array}{l}\text { Sha and Huang } \\
\text { (2012) }\end{array}$ & $\begin{array}{l}\text { Earthquakes emergency } \\
\text { blood }\end{array}$ & Heuristic Algorithm and Lagrangian Relaxation (LR) \\
\hline & $\begin{array}{l}\text { Fazel Zarandi et al. } \\
\text { (2013) }\end{array}$ & $\begin{array}{l}\text { Maximal covering location } \\
\text { problem }\end{array}$ & Simulated Annealing (SA) \\
\hline & $\begin{array}{l}\text { Ghaderi and } \\
\text { Jabalameli (2013) }\end{array}$ & Health care & $\begin{array}{l}\text { Branch and Bound, Hybrid Greedy Heuristic and Fix-and- } \\
\text { Optimize Heuristic and Hybrid Simulated Annealing (SA) }\end{array}$ \\
\hline & $\begin{array}{l}\text { Nadizadeh and } \\
\text { Hosseini Nasab } \\
\text { (2014) }\end{array}$ & Location routing problem & $\begin{array}{l}\text { Hybrid Heuristic Algorithm (HHA) and Fuzzy Credibility } \\
\text { Theory }\end{array}$ \\
\hline & $\begin{array}{l}\text { Archetti et al. } \\
\text { (2015) }\end{array}$ & Vehicle routing problem & Branch-and-Cut \\
\hline & $\begin{array}{l}\text { Barkaoui and } \\
\text { Boukhtouta (2015) }\end{array}$ & $\begin{array}{l}\text { Vehicle routing problem and } \\
\text { customers satisfaction }\end{array}$ & Hybrid Genetic Algorithm (GA) \\
\hline & $\begin{array}{l}\text { De Armas and } \\
\text { Melián-Batista } \\
(2015)\end{array}$ & Vehicle routing problem & Variable Neighborhood Search (VNS) \\
\hline \multirow[t]{4}{*}{ Education systems } & $\begin{array}{l}\text { Henig and Gerchak } \\
\text { (1986) }\end{array}$ & $\begin{array}{l}\text { Public school in changing } \\
\text { urban communities }\end{array}$ & Dynamic Programming (DP) \\
\hline & $\begin{array}{l}\text { Antunes and Peeters } \\
(2000)\end{array}$ & $\begin{array}{l}\text { School network planning } \\
\text { (location-allocation } \\
\text { problem) }\end{array}$ & Heuristic and Simulated Annealing (SA) \\
\hline & $\begin{array}{l}\text { Antunes and Peeters } \\
\text { (2001) }\end{array}$ & $\begin{array}{l}\text { School network planning } \\
\text { (location-allocation } \\
\text { problem) }\end{array}$ & Heuristic and Simulated Annealing (SA) \\
\hline & $\begin{array}{l}\text { Benneyan et al. } \\
\text { (2012) }\end{array}$ & $\begin{array}{l}\text { Veterans health care } \\
\text { (location-allocation } \\
\text { problem) }\end{array}$ & Exact \\
\hline \multirow{3}{*}{$\begin{array}{l}\text { Emergency medical } \\
\text { service (EMS) } \\
\text { systems }\end{array}$} & Schilling (1980) & - & Heuristic Algorithm and Weighted Method \\
\hline & $\begin{array}{l}\text { Gendreau et al. } \\
\text { (2001) }\end{array}$ & - & Tabu Search (TS) and Heuristic Algorithm \\
\hline & $\begin{array}{l}\text { Brotcorne et al. } \\
\text { (2003) }\end{array}$ & - & Exact \\
\hline
\end{tabular}


Table 5 continued

\begin{tabular}{|c|c|c|c|}
\hline $\begin{array}{l}\text { Applications of } \\
\text { location problem }\end{array}$ & Author's (year) & Description fields of applications & Solution technique \\
\hline & $\begin{array}{l}\text { Rajagopalan et al. } \\
\text { (2008) }\end{array}$ & - & Tabu search (TS) and heuristic algorithm \\
\hline $\begin{array}{l}\text { Miskovic et al. } \\
\text { (2015) }\end{array}$ & $\begin{array}{l}\text { Police special } \\
\text { forces units } \\
\text { (PSFUs) }\end{array}$ & $\begin{array}{l}\text { Variable neighborhood search } \\
\text { (VNS) }\end{array}$ & \\
\hline \multirow[t]{8}{*}{ Hub systems } & $\begin{array}{l}\text { Contreras et al. } \\
\text { (2010) }\end{array}$ & Hub location & Branch-and-Bound and Lagrangian Relaxation (LR) \\
\hline & $\begin{array}{l}\text { Teymourian et al. } \\
\text { (2011) }\end{array}$ & $\begin{array}{l}\text { Hub location routing (airline } \\
\text { networks) }\end{array}$ & Hybrid Simulated Annealing \\
\hline & Correia et al. (2012) & $\begin{array}{l}\text { Hub location (transportation } \\
\text { networks) }\end{array}$ & Heuristic Approach \\
\hline & $\begin{array}{l}\text { Taghipourian et al. } \\
\text { (2012) }\end{array}$ & $\begin{array}{l}\text { Hub location routing (airline } \\
\text { networks) }\end{array}$ & Fuzzy Programming Approach \\
\hline & Horhammer (2014) & Hub location (post network) & Exact \\
\hline & $\begin{array}{l}\text { Marufuzzaman and } \\
\text { Eksioglu (2014) }\end{array}$ & $\begin{array}{l}\text { Intermodal hub and spoke supply } \\
\text { chain for biomass }\end{array}$ & Bender's Decomposition \\
\hline & $\begin{array}{l}\text { Bashiri and } \\
\text { Hamidian (2015) }\end{array}$ & Hub location (airline networks) & Exact, Simulated Annealing (SA) \\
\hline & $\begin{array}{l}\text { Gelareh et al. } \\
(2015)\end{array}$ & Hub location (terminals network) & Bender's Decomposition, Metaheuristic Algorithm \\
\hline \multirow{14}{*}{$\begin{array}{l}\text { Production- } \\
\text { distribution } \\
\text { systems }\end{array}$} & Ballou (1968) & Warehouse location problem & Dynamic Programming (DP) \\
\hline & $\begin{array}{l}\text { Sweeney and } \\
\text { Tatham (1976) }\end{array}$ & - & Dynamic Programming (DP) and Bender's Decomposition \\
\hline & $\begin{array}{l}\text { VanRoy and } \\
\text { Erlenkotter } \\
\text { (1982) }\end{array}$ & - & $\begin{array}{l}\text { Heuristic Dual Ascent Algorithm [Branch-and-Bound and } \\
\text { Lagrangian Relaxation (LR)] }\end{array}$ \\
\hline & $\begin{array}{l}\text { Kelly and } \\
\text { Marucheck } \\
\text { (1984) }\end{array}$ & Warehouse location problem & Bender's Decomposition \\
\hline & $\begin{array}{l}\text { Min and } \\
\text { Melachrinoudis } \\
\text { (1999) }\end{array}$ & Warehouse location problem & Analytic Hierarchy Process (AHP) \\
\hline & $\begin{array}{l}\text { Hinojosa et al. } \\
\text { (2000) }\end{array}$ & $\begin{array}{l}\text { Two-echelon plant-warehousing } \\
\text { facility }\end{array}$ & $\begin{array}{l}\text { Branch-and-Bound and Lagrangian Relaxation (LR) and } \\
\text { Heuristic Algorithm }\end{array}$ \\
\hline & $\begin{array}{l}\text { Melachrinoudis and } \\
\text { Min (2000) }\end{array}$ & $\begin{array}{l}\text { Two-echelon plant-warehousing } \\
\text { facility }\end{array}$ & Weighted method \\
\hline & $\begin{array}{l}\text { Alonso-Ayuso et al. } \\
\text { (2003) }\end{array}$ & $\begin{array}{l}\text { Bills of material (BoM) and plant } \\
\text { sizing and vendor selection }\end{array}$ & Branch-and-fix coordination (BFC) algorithm \\
\hline & $\begin{array}{l}\text { Romeijn and } \\
\text { Morales (2004) }\end{array}$ & $\begin{array}{l}\text { Inventory and transportation } \\
\text { planning }\end{array}$ & Greedy heuristic \\
\hline & Aghezzaf (2005) & Warehouse location problem & $\begin{array}{l}\text { Robust optimization (RO) and decomposition algorithm, } \\
\text { lagrangian relaxation (LR) }\end{array}$ \\
\hline & $\begin{array}{l}\text { Gen and Syarif } \\
(2005)\end{array}$ & $\begin{array}{l}\text { Design of production/distribution } \\
\text { and inventory }\end{array}$ & Spanning Tree Based Genetic Algorithm (hst-GA) \\
\hline & Melo et al. (2005) & $\begin{array}{l}\text { Inventory, transportation and } \\
\text { supply planning }\end{array}$ & Branch-and-Bound \\
\hline & $\begin{array}{l}\text { Romauch and Hartl } \\
\text { (2005) }\end{array}$ & Warehouse location problem & $\begin{array}{l}\text { Stochastic dynamic programming and heuristic algorithm } \\
\text { [monte carlo and sample average approximation (SAA)] }\end{array}$ \\
\hline & $\begin{array}{l}\text { Behmardi and Lee } \\
\text { (2008) }\end{array}$ & - & Branch-and-Bound \\
\hline
\end{tabular}


Table 5 continued

\begin{tabular}{|c|c|c|c|}
\hline $\begin{array}{l}\text { Applications of } \\
\text { location problem }\end{array}$ & Author's (year) & Description fields of applications & Solution technique \\
\hline & $\begin{array}{l}\text { Hinojosa et al. } \\
\text { (2008) }\end{array}$ & Supply chain with inventory & $\begin{array}{l}\text { Branch-and-Bound and Lagrangian Relaxation } \\
\text { (LR) and Heuristic Algorithm }\end{array}$ \\
\hline & $\begin{array}{l}\text { Manzini and } \\
\text { Gebennini } \\
(2008)\end{array}$ & $\begin{array}{l}\text { Logistic distribution system (two-stage facility } \\
\text { location and allocation problem) }\end{array}$ & Exact \\
\hline & $\begin{array}{l}\text { Thanh et al. } \\
\text { (2008) }\end{array}$ & - & Branch-and-Bound \\
\hline & Acar et al. (2009) & Inventory and transportation planning & Exact \\
\hline & $\begin{array}{l}\text { Gebennini et al. } \\
\text { (2009) }\end{array}$ & $\begin{array}{l}\text { Supply Chain (location-allocation problem) } \\
\text { with Inventory }\end{array}$ & Exact \\
\hline & $\begin{array}{l}\text { Mahar et al. } \\
\text { (2009) }\end{array}$ & Supply chain (regional warehouse locations) & Branch-and-bound and dynamic programming \\
\hline & $\begin{array}{l}\text { Naraharisetti and } \\
\text { Karimi (2010) }\end{array}$ & Supply chain with inventory & Exact \\
\hline & Sepehri (2011) & Supply chain cooperative & Exact \\
\hline & Carle et al. (2012) & $\begin{array}{l}\text { Supply chain network design [vendor selection } \\
\text { and collaborative agent team }(\mathrm{CAT})]\end{array}$ & Exact \\
\hline & $\begin{array}{l}\text { Correia et al. } \\
\text { (2013) }\end{array}$ & Supply chain network design problem & Exact \\
\hline & $\begin{array}{l}\text { Jouzdani et al. } \\
\text { (2013) }\end{array}$ & Supply chain planning (dairy facility location) & Fuzzy programming approach \\
\hline & $\begin{array}{l}\text { Cucek et al. } \\
\text { (2014) }\end{array}$ & Biomass and bioenergy supply network & Exact \\
\hline & $\begin{array}{l}\text { Zeballos et al. } \\
\text { (2014) }\end{array}$ & Closed-loop supply chains (CLSCs) & Exact \\
\hline & $\begin{array}{l}\text { Dayarian et al. } \\
\text { (2015) }\end{array}$ & $\begin{array}{l}\text { Vehicle routing problem [service reliability } \\
\text { threshold }(\mathrm{srt}) \text { ] }\end{array}$ & $\begin{array}{l}\text { Dynamic programming (DP), column } \\
\text { generation and branch-and-price, tabu search } \\
\text { (TS) }\end{array}$ \\
\hline & $\begin{array}{l}\text { Fattahi et al. } \\
\text { (2015) }\end{array}$ & Supply chain network & $\begin{array}{l}\text { Linear relaxation heuristic and simulated } \\
\text { annealing (SA) }\end{array}$ \\
\hline $\begin{array}{l}\text { Solid Waste } \\
\text { Management } \\
\text { Systems }\end{array}$ & $\begin{array}{l}\text { Melachrinoudis } \\
\text { et al. (1995) }\end{array}$ & Hazardous garbage & Weighted method \\
\hline \multirow[t]{2}{*}{$\begin{array}{l}\text { Telecommunications } \\
\text { Networks }\end{array}$} & $\begin{array}{l}\text { Chardaire et al. } \\
\text { (1996) }\end{array}$ & $\begin{array}{l}\text { Telecommunication and intelligent network } \\
\text { (location-allocation problem) }\end{array}$ & Lagrangian relaxation and heuristic \\
\hline & $\begin{array}{l}\text { Gourdin and } \\
\text { Klopfenstein } \\
\text { (2008) }\end{array}$ & $\begin{array}{l}\text { Telecommunication access network planning } \\
\text { problem }\end{array}$ & Exact \\
\hline
\end{tabular}

- Dynamic facility location models are vastly used in general facility location problems. In most recent papers, single services for customers have been considered, while, variety of services expand the model to introduce the hierarchical problem with different levels, flow pattern and configuration of network. In this time, we can understand the importance of hierarchical location problem, which is studied by Melachrinoudis et al. (1995), Hinojosa et al. (2000), Melachrinoudis and Min (2000), Syam (2002), Dias et al. (2007b), Dias et al. (2008a), Manzini and Gebennini (2008), Thanh et al. (2008) and Gebennini et al. (2009); needs to be focused more.
- To manage demanding customers more efficiently and also satisfy demands faster, systems should be designed such as capable of managing several facilities (several systems) instead of one facility (one system). Actually some papers are written about this subject, but having several facilities in dynamic location problem (DLP) needs to be attended.

- Considering multi-facilities (multi-systems) to satisfy demands, brings facility (systems) competitions that only Miller (2007) and Bozkaya (2010) have attended. Having competitive facility, pricing and coalition of systems in dynamic location problem (DLP) can be another field to study. 
Table 6 Real-life case for DLPs

\begin{tabular}{|c|c|c|c|}
\hline $\begin{array}{l}\text { Applications of location } \\
\text { problem }\end{array}$ & Author's (year) & Real-life case study & Place (city) \\
\hline Competitive systems & Bozkaya et al. (2010) & Supermarket store chain in a major metropolitan city & Turkey (Istanbul) \\
\hline \multirow[t]{9}{*}{ Distribution systems } & Erlenkotter (1981) & Indian caustic soda & Indian \\
\hline & $\begin{array}{l}\text { Frantzeskakis and } \\
\text { Watson-Gandy (1989) }\end{array}$ & Distribution industry & - \\
\hline & $\begin{array}{l}\text { Canel and Khumawala } \\
\text { (1997) }\end{array}$ & Agricultural chemicals international & United States \\
\hline & $\begin{array}{l}\text { Ambrosino and Scutella } \\
\text { (2005) }\end{array}$ & Distribution network design problem & Italy \\
\hline & Wen et al. (2010) & Bioenergy and agriculture (Dataset Lantmannen) & Sweden \\
\hline & Sha and Huang (2012) & Earthquakes emergency blood supply Systems & Beijing \\
\hline & $\begin{array}{l}\text { Ghaderi and Jabalameli } \\
\text { (2013) }\end{array}$ & Health care & Iran (Illam) \\
\hline & $\begin{array}{l}\text { De Armas and Melián- } \\
\text { Batista (2015) }\end{array}$ & Vehicle routing problem & - \\
\hline & $\begin{array}{l}\text { Barkaoui and Boukhtonta } \\
\text { (2015) }\end{array}$ & $\begin{array}{l}\text { Vehicle routing problem and customers satisfaction (100 } \\
\text { customers) }\end{array}$ & - \\
\hline \multirow[t]{3}{*}{ Education systems } & Henig and Gerchak (1986) & Public schools in changing urban communities & Israel \\
\hline & $\begin{array}{l}\text { Antunes and Peeters } \\
(2000)\end{array}$ & School network planning & Portuguese \\
\hline & $\begin{array}{l}\text { Antunes and Peeters } \\
\text { (2001) }\end{array}$ & School network planning & Portugal \\
\hline \multirow{5}{*}{$\begin{array}{l}\text { Emergency medical service } \\
\text { (EMS) systems }\end{array}$} & Schilling (1980) & Locating emergency services & - \\
\hline & Gendreau et al. (2001) & Dynamic ambulance management system & - \\
\hline & Brotcorne et al. (2003) & Ambulance location and relocation models & - \\
\hline & Benneyan et al. (2012) & Veterans health administration & New York \\
\hline & Miskovic et al. (2015) & $\begin{array}{l}\text { Emergency service network of Police Special forces units } \\
\text { (PSFUs) }\end{array}$ & Republic of Serbia \\
\hline \multirow[t]{6}{*}{ Hub systems } & Teymourian et al. (2011) & Dynamic-demand capacitated facility location & Turkish \\
\hline & Taghipourian et al. (2012) & Airline network (CAB Dataset) & Turkish \\
\hline & Horhammer, (2014) & Airline network (CAB Dataset) & Turkish \\
\hline & $\begin{array}{l}\text { Marufuzzaman and } \\
\text { Eksioglu (2014) }\end{array}$ & Post network (AP Dataset), 200 Postcode in Sydney & Australia (Sydney) \\
\hline & $\begin{array}{l}\text { Bashiri and Hamidian } \\
\quad(2015)\end{array}$ & Biofuel supply chain & USA (Southeast region) \\
\hline & Gelareh et al. (2015) & $\begin{array}{l}\text { Post network (AP Dataset), } 200 \text { Postcode in Sydney and } \\
\text { Airline network (CAB Dataset) }\end{array}$ & $\begin{array}{l}\text { Australia (Sydney) and } \\
\text { Turkish }\end{array}$ \\
\hline \multirow[t]{10}{*}{$\begin{array}{l}\text { Production-distribution } \\
\text { systems }\end{array}$} & $\begin{array}{l}\text { Kelly and Marucheck } \\
\text { (1984) }\end{array}$ & Warehousing Facility & - \\
\hline & $\begin{array}{l}\text { Min and Melachrinoudis } \\
\text { (1999) }\end{array}$ & $\begin{array}{l}\text { Relocation of a combined manufacturing and distribution } \\
\text { (warehousing) Facility }\end{array}$ & United States \\
\hline & $\begin{array}{l}\text { Melachrinoudis and Min } \\
\text { (2000) }\end{array}$ & Manufacturing and warehousing facility & United states (Boston) \\
\hline & $\begin{array}{l}\text { Manzini and Gebennini } \\
\text { (2008) }\end{array}$ & Leading electronic company (AS-IS) & $\begin{array}{l}\text { Italy, UK, France, Germany, } \\
\text { Taiwan and USA }\end{array}$ \\
\hline & Gebennini et al. (2009) & Leading electronic company (AS-IS) & $\begin{array}{l}\text { Italy, UK, France, Germany, } \\
\text { Taiwan and USA }\end{array}$ \\
\hline & Mahar et al. (2009) & Retailer's capacitated regional warehouse locations & United State \\
\hline & $\begin{array}{l}\text { Naraharisetti and Karimi } \\
\text { (2010) }\end{array}$ & Supply chain with four raw material suppliers & - \\
\hline & Carle et al. (2012) & B2B company manufacturing and selling products & United States \\
\hline & Jauzdani et al. (2013) & Dairy facility location & Iran (Tehran) \\
\hline & Cucek et al. (2014) & Biomass and bioenergy supply network & $\begin{array}{l}\text { United States (US) and } \\
\text { European Union (EU) }\end{array}$ \\
\hline $\begin{array}{l}\text { Solid waste management } \\
\text { systems }\end{array}$ & $\begin{array}{l}\text { Melachrinoudis et al. } \\
\text { (1995) }\end{array}$ & Dynamic location of landfills & - \\
\hline $\begin{array}{l}\text { Telecommunications } \\
\text { networks }\end{array}$ & Chardaire et al. (1996) & Intelligent networks & - \\
\hline
\end{tabular}


- Combination of continuous models in dynamic location problem (DLP) is one of the fields that is attended less. Almost in all the published papers, time and location of relocation is considered as discrete points. Hence, attending to continuous models and combining that with dynamic location problem (DLP) can have more realistic results than discrete models.

- In recent years the events happened suddenly and in numbers, so in DLPs, the crisis management needs to be considered in case studies. In real-world logistic problems, system operates in two different moods: normal and abnormal (crisis).

- Normal mood of system is when there are no threats or changes. Planning for logistic relief management in crisis which includes two parts: natural crisis and byhuman crisis (such as earthquake, flood, storm and war) means considering uncertainties, to confront sudden happenings; this problem is one of the matters that should be studied more in dynamic location problem (DLP) systems.

- Also sustainability of modeling and paying attention to particular points like social, cultural and political factors, environmental effects, green supply chain and attending to logistic systems pollution have economic aspects, can be one of the most important challenges in dynamic location problem (DLP).

- In all the distribution systems, waiting time, which means the time that customers can wait until they get the services they want has significant impression on their decision, and in location problem it is called queue (queuing theory). Designing a system optimally without having a sight on density and bottleneck made by customers waiting for services, is not possible. Dynamic location problem (DLP) approaches need to get merged with methods like queuing theory that can be more synchronized or adapted with real conditions of every system, namely existence of queue.

- When a group of facilities gets set up, in every period of time, it is possible that one or some of them, suddenly disrupt or destroy and this can have several reasons such as depreciation as a result of long-term usage, environmental or political elements and so on, and it is unavoidable. Hence, considering the possibility of disruption and the risk of destruction increases the reliability of developed models. Nadizadeh and Hosseini Nasab (2014) have studied it in dynamic location problem (DLP). This matter can be studied as a research subject that is attended little yet.

- In most of the existing models of the literature, parameters of models are taken as deterministic ones; however, in real world they are uncertain. It is not possible to forget the probabilistic and stochastic essence of dynamic location problem (DLP). Having uncertain input parameters cause to use Probabilistic Programming (PP), Stochastic Programming (SP), Fuzzy Approach and Robust Optimization (RO) or other optimizing methods and also combining them we can confront uncertainty. Considering the uncertainty is one of the primaries in this field.

- Attention to the limitation of sources and capacities in location problems is essential. Sources and capacities of facilities have been considered changeless during the horizon planning till now so with regards to dynamic system argument it is clear that reachable sources and capacities of facilities are changing during the time and can have increases or decreases hence it is possible to have a backup system to confront the lack of enough sources and capacities. Thus, considering to existing constraints in real world improves the DLP modeling.

- Application of new objective functions instead of considering the allocation based on the closest facility or minimizing the costs and distances, or maximum benefit is the factor that should be considered, regarding time conditions during the time horizon. Multi-objective functions with several criteria in bi-level, multilevel, bi-stage and multi-stage, with more complex objectives, can conduct us to a more real condition.

- Solution approaches are divided into two parts: exact solution, heuristic and metaheuristic solution. In DLPs, exact algorithm is not developed with time passing. Regarding the complexity of DLPs, algorithms developing is hard. For this reason, heuristic and metaheuristic algorithms or a combination of them are more attended in this subject. However, these methods, will not give us an accurate solution; hence, using some techniques to have a better analysis of these approaches, combining them and developing existing methods can produce a better condition in DLP solutions.

\section{Compliance with ethical standards}

Conflict of interest The authors declare that they have no competing interests.

Open Access This article is distributed under the terms of the Creative Commons Attribution 4.0 International License (http://crea tivecommons.org/licenses/by/4.0/), which permits unrestricted use, distribution, and reproduction in any medium, provided you give appropriate credit to the original author(s) and the source, provide a link to the Creative Commons license, and indicate if changes were made.

\section{References}

Abravaya S, Berend D (2009) Multi-dimensional dynamic facility location and fast computation at query points. Inf Process Lett 109:386-390 
Acar Y, Kadipasaoglu SN, Day JM (2009) Incorporating uncertainty in optimal decision making: integrating mixed integer programming and simulation to solve combinatorial problems. Comput Ind Eng 56:106-112

Aghezzaf E (2005) Capacity planning and warehouse location in supply chains with uncertain demands. J Oper Res Soc $56: 453-462$

Albareda-Sambola M, Fernández E, Hinojosa Y, Puerto J (2009) The multi-period incremental service facility location problem. Comput Oper Res 36:1356-1375

Alonso-Ayuso A, Escudero LF, Garin A, Ortuno MT, Perez G (2003) An approach for strategic supply chain planning under uncertainty based on stochastic $0-1$ programming. J Global Optim 26:97-124

Ambrosino D, Grazia Scutella M (2005) Distribution network design: new problems and related models. Eur J Oper Res 165:610-624

Andreatta G, Mason FM (1994) A note on "a perfect forward procedure for a single facility dynamic location/relocation problem”. Oper Res Lett 9:81-83

Antunes A, Peeters D (2000) A dynamic optimization model for school network planning. Socio Econ Plan Sci 34:101-120

Antunes A, Peeters D (2001) On solving complex multi-period location models using simulated annealing. Eur J Oper Res 130:190-201

Arabani AB, Farahani RZ (2012) Facility location dynamics: an overview of classifications and applications. Comput Ind Eng 62:408-420

Archetti C, Jabali O, Speranza GG (2015) Multi-period vehicle routing problem with due dates. Comput Oper Res 61:122-134

Averbakh I, Berman O, Drezner Z, Wesolowsky GO (1998) The plant location problem with demand-dependent setup costs and centralized allocation. Eur J Oper Res 111:543-554

Averbakh I, Berman O, Drezner Z, Wesolowsky GO (2007) The uncapacitated facility location problem with demand-dependent setup and service costs and customer-choice allocation. Eur J Oper Res 179:956-967

Ballou RH (1968) Dynamic warehouse location analysis. J Mark Res 5:271-276

Barkaoui M, Berger J, Boukhtouta A (2015) Customer satisfaction in dynamic vehicle routing problem with time windows. Appl Soft Comput 35:423-432

Bashiri M, Hamidian K (2015) A dynamic median multiple allocation hub location problem. Prod Oper Manag 5:93-108

Bastian M, Volkmer M (1992) A perfect forward procedure for a single facility dynamic location/relocation problem. Oper Res Lett 12:11-16

Behmardi B, Lee Sh (2008) Dynamic multi-commodity capacitated facility location problem in supply chain. Proceedings of the 2008 industrial engineering research conference 1914-1919

Bellman R (1975) Dynamic programming. Press, Princeton

Benders JF (1962) Partitioning procedures for solving mixedvariables programming problems. Numer Math 4(3):238-252

Benneyan JC, Musdal H, Ceyhan ME, Shiner B, Watts BV (2012) Specialty care single and multi-period location-allocation models within the veterans' health administration. Socio Econ Plan Sci 46:136-148

Bozkaya B, Yanik S, Balcisoy S (2010) A GIS-based optimization framework for competitive multi-facility location-routing problem. Netw Spat Econ 10:297-320

Brotcorne L, Laporte G, Semet F (2003) Ambulance location and relocation models. Eur J Oper Res 147:451-463

Campbell JF (1990) Location transportation terminals to serve an expanding demand. Transp Res Part B Methodol 24:173-192

Canel C, Khumawala BM (1997) Multi-period international facilities location: an algorithm and application. Int $\mathrm{J}$ Prod Res 35:1891-1910
Canel C, Khumawala BM, Law J, Loh A (2001) An algorithm for the capacitated, multi-commodity multi-period facility location problem. Comput Oper Res 28:411-427

Carle MA, Martel A, Zufferey N (2012) The CAT metaheuristic for the solution of multi-period activity-based supply chain network design problems. Int J Prod Econ 139:664-677

Chardaire P, Sutter A, Costa MC (1996) Solving the dynamic facility location problem. Networks 28:117-124. doi:10.1002/ (SICI) 1097-0037(199609)28:2<117:AID-NET5>3.0.CO;2-H

Contreras I, Cordeau JF, Laporte G (2010) The dynamic uncapacitated hub location problem. Transp Sci 45:18-32

Correia I, Gelareh Sh, Nickel S, Saldanha-da-Gama F (2012) Multiperiod hub location problems in transportation networks. Working Paper

Correia I, Melo T, Saldanga-da-Gama F (2013) Comparing classical performance measures for a multi-period, two-echelon supply chain network design problem with sizing decisions. Comput Ind Eng 64:366-380

Cucek L, Martin M, Grossmann E, Kravanja Z (2014) Multi-period synthesis of optimally integrated biomass and bioenergy supply network. Comput Chem Eng 66:57-70

Current J, Ratick S, ReVelle C (1997) Dynamic facility location when the total number of facilities is uncertain: a decision analysis approach. Eur J Oper Res 110:597-609

Daskin MS, Hopp WJ, Medina B (1992) Forecast horizon and dynamic facility location planning. Ann Oper Res 40:125-151

Dayarian I, Crainic TG, Gendreau M, Rei W (2015) A branch-andprice approach for a multi-period vehicle routing problem. Comput Oper Res 55:167-184

De Armas J, Melian-Batista B (2015) Variable neighborhood search for a dynamic rich vehicle routing problem with time windows. Comput Ind Eng 85:120-131

Dias J, Captivo ME, Clímaco J (2006) Capacitated dynamic location problems with opening, closure and reopening of facilities. IMA J Manag Math 17:317-348

Dias J, Captivo ME, Clímaco J (2007a) Dynamic location problems with discrete expansion and reduction sizes of available capacities. Investigação Operacional 27:107-130

Dias J, Captivo ME, Clímaco J (2007b) Efficient primal-dual heuristic for a dynamic location problem. Comput Oper Res 34:1800-1823

Dias J, Captivo ME, Clímaco J (2008a) A dynamic location problem with maximum decreasing capacities. CEJOR 16:251-280

Dias J, Captivo ME, Clímaco J (2008b) A memetic algorithm for multi-objective dynamic location problems. J Glob Optim 42:221-253

Dias J, Captivo ME, Clímaco J (2008c) Dynamic multi-level capacitated and uncapacitated location problems: an approach using primal-dual heuristics. Oper Res Int J 7:345-379

Drezner Z, Wesolowsky GO (1991) Facility location when demand is time dependent. Naval Res Logist 38:763-777

Emamizadeh B, Farahani RZ (1997a) Facility location and relocation in global manufacturing strategy. FAIM conference, Middlesbrough, England

Emamizadeh B, Farahani RZ (1997b) Facility location and relocation with time-dependent weight. DSI Conference, Sidney, Australia

Erlenkotter D (1981) A comparative study of approaches to dynamic location problem. Eur J Oper Res 6:133-143

Farahani RZ, Hekmatfar M (2009) Facility location: concepts, models, algorithms and case studies. Springer, Dordrecht, pp 347-372

Farahani RZ, Drezner Z, Asgari N (2009) Single facility location and relocation problem with time-dependent weights and discrete planning horizon. Ann Oper Res 167:353-368

Farahani RZ, Hekmatfar M, Fahimnia B, Kazemzadeh N (2014) Hierarchical facility location problem: models, classifications, techniques, and applications. Comput Ind Eng 68:104-117 
Fattahi M, Mahootchi M, Govindan K, Moattar Husseini SM (2015) Dynamic supply chain network design with capacity planning and multi-period pricing. Transp Res Part E Logist Transp Rev 81:169-202

Fazel Zarandi MH, Davari S, Haddad Sisakht SA (2013) The largescale dynamic maximal covering location problem. Math Comput Model 57:710-719

Fisher ML (1981) The Lagrangian relaxation method for solving integer programming problems. Manage Sci 27:1-18

Frantzeskakis M, Watson-Gandy CDT (1989) The use of state space relaxation for the dynamic facility location problem. Ann Oper Res 18:187-211

Gabor AF, Van Ommeren JCW (2006) An approximation algorithm for a facility location problem with stochastic demands and inventories. Oper Res Lett 34:257-263

Galvao RD, Santibanez-Gonzalez EDR (1992) A lagrangean heuristic for the p-median dynamic location problem. Eur J Oper Res 58:250-262

Gebennini E, Gamberini R, Manzini R (2009) An integrated production-distribution model for the dynamic Location and allocation problem with safety stock optimization. Int J Prod Econ 122:286-304

Gelareh Sh, Neamatian Monemi R, Nickel S (2015) Multi-period hub location problems in transportation. Transp Res Part E Logist Transp Rev 75:67-94

Gen M, Syarif A (2005) Hybrid genetic algorithm for multi-time period production/distribution planning. Comput Ind Eng 48:799-809

Gendreau M, Laporte G, Semet F (2001) A dynamic model and parallel tabu search heuristic for real time ambulance Relocation. Parallel Comput 27:1641-1653

Ghaderi A, Jabalameli MS (2013) Modeling the budget-constrained dynamic uncapacitated facility location-network design problem and solving it via two efficient heuristics: a case study of health care. Math Comput Model 57:382-400

Glover F (1986) Future paths for Integer programming and links to artificial intelligence. Comput Oper Res 13(5):533-549. doi:10. 1016/0305-0548(86)90048-1

Gourdin E, Klopfenstein O (2008) Multi-period capacitated location with modular equipment's. Comput Oper Res 35:661-682

Gue KR (2003) A dynamic distribution model for combat logistics. Comput Oper Res 30:367-381

Gunawardane G (1982) Dynamic versions of set covering type public facility location problems. Eur J Oper Res 10:190-195

Henig M, Gerchak Y (1986) Dynamic capacity planning of public schools in changing urban communities. Socio Econ Plan Sci 20:319-324

Hinojosa Y, Puerto J, Fernandez FR (2000) A multi-period twoechelon multi-commodity capacitated plant location problem. Eur J Oper Res 123:271-291

Hinojosa Y, Kalcsics J, Nickel S, Puerto J, Velten S (2008) Dynamic supply chain design with inventory. Comput Oper Res 35:373-391

Holland JH (1992) Adaptation in natural and artificial systems. MIT, Massachusetts

Horhammer AMC (2014) Dynamic hub location problems with single allocation and multiple capacity levels. 47th Hawaii International Conference on System Science, IEEE Computer Society 994-1003

Hormozi AM, Khumawala BM (1996) An improved algorithm for solving a multi-period facility location problem. IIE Trans 28:105-114

Jawahar N, Balaji N (2012) A genetic algorithm based heuristic to the multi-period fixed charge distribution problem. Appl Soft Comput 12:682-699
Jouzdani J, Sadjadi SJ, Fathian M (2013) Dynamic dairy facility location and supply chain planning under traffic congestion and demand uncertainty: a case study of Tehran. Appl Math Model 37:8467-8483

Kelly D, Marucheck AS (1984) Planning horizon results for the dynamic warehouse location problem. J Oper Manag 4:279-294

Kirkpatrick S, Gelatt CD, Vecchi MP (1983) Optimization by simulated annealing. Science 220:671-680

Land AH, Doig AG (1960) An automatic method of solving discrete programming problems. Econometrica 28:497-520. doi:10.2307/ 1910129

Lau HCW, Jiang ZhZh, Ip WH, Wang D (2010) A credibility-based fuzzy location model with hurwicz criteria for the design of distribution systems in B2C e-commerce. Comput Ind Eng 59:873-886

Lee DJ, Jeong IJ (2009) Regression approximation for a partially centralized inventory system considering transportation costs. Comput Ind Eng 56:1169-1176

Mahar S, Bretthauer KM, Venkataramanan MA (2009) An algorithm for solving the multi-period online fulfillment assignment problem. Math Comput Model 50:1294-1304

Manzini R, Gebennini E (2008) Optimization models for the dynamic facility location and allocation problem. Int $\mathrm{J}$ Prod Res 46:2061-2086

Marufuzzaman M, Eksioglu SD (2014) Developing a reliable and dynamic intermodal hub and spoke supply chain for biomass. IIE Annual Conference and Expo 2014, Institute of Industrial Engineers Montreal 2417-2426

Melachrinoudis E, Min H (2000) The dynamic relocation and phaseout of a hybrid, two-echelon plant/warehousing facility: a multiple objective approach. Eur J Oper Res 123:1-15

Melachrinoudis E, Min H, Wu X (1995) A multi-objective model for the dynamic location of landfills. Locat Sci 3:143-166

Melo MT, Nickel S, Saldanha da Gama F (2005) Dynamic multicommodity capacitated facility location: a mathematical modeling framework for strategic supply chain planning. Comput Oper Res 33:181-208

Miller TC, Friesz TL, Tobin RL, Kwon C (2007) Reaction function based dynamic location modelling in stackelberg-nash-cournot competition. Netw Spat Econ 7:77-97

Min H, Melachrinoudis E (1999) The relocation of a hybrid manufacturing/distribution facility from supply chain perspectives: a case study. Omega 27:75-85

Miskovic S, Stanimirovic Z, Grujicic I (2015) An efficient variable neighborhood search for solving a robust dynamic facility location problem in emergency service network. Electron Notes Discret Math 47:261-268

Nadizadeh A, Hosseini Nasab H (2014) Solving the dynamic capacitated location-routing problem with fuzzy demands by hybrid heuristic algorithm. Eur J Oper Res 238:458-470

Naraharisetti PK, Karimi IA (2010) Supply chain redesign and new process introduction in multipurpose plants. Chem Eng Sci 65(8):2596-2607

Owen SH, Daskin MS (1998) Strategic facility location: a review. Eur J Oper Res 111:423-447

Rajagopalan HK, Saydam C, Xiao J (2008) A multi-period set covering location model for dynamic redeployment of ambulances. Comput Oper Res 35:814-826

Romauch M, Hartl RF (2005) Dynamic facility location with stochastic demands. Stoch Algorithm Found Appl 3777:180-189

Romeijn HE, Romero Morales D (2004) Asymptotic analysis of a greedy heuristic for the multi-period single-sourcing problem: the acyclic case. J Heuristics 10:5-35

Roodman GM, Schwarz LB (1977) Extensions of the multi-period facility phase-out model: new procedures and application to a 
phase -in/phase-out problem. IIE Trans 9:103-107. doi:10.1080/ 05695557708975128

Rosenthal RE, White JA, Young D (1978) Stochastic dynamic location analysis. Manage Sci 24:645-653

Saldanha-da-Gama F, Captivo ME (1998) A heuristic approach for the discrete dynamic location problem. Loc Sci 6:211-223

Schiling DA (1980) Dynamic location modeling for public-sector facilities: a multi-criteria approach. Decis Sci 11:714-724

Scott AJ (1971) Dynamic location-allocation systems: some basic planning strategies. Environ Plan 3:73-82

Sepehri M (2011) Cost and inventory benefits of cooperation in multiperiod and multi-product supply. Scientia Iranica E 18:731-741

Sha Y, Huang J (2012) The multi-period location-allocation problem of engineering emergency blood supply systems. Systems Engineering Procedia 5:21-28

Sherali HD (1991) Capacitated, balanced, sequential location-allocation problems on chains and trees. Math Program 49:381-396

Shulman A (1991) An algorithm for solving dynamic capacitated plant location. Oper Res 39:423-436

Sweeney DJ, Tatham RL (1976) An improved long-run model for multiple warehouse location. Manage Sci 22:748-758

Syam SS (2002) A model and methodologies for the location problem with logistical components. Comput Oper Res 29:1173-1193

Taghipourian F, Mahdavi I, Mahdavi-Amiri N, Makui A (2012) A fuzzy programming approach for dynamic virtual hub location problem. Appl Math Model 36:3257-3270

Tapiero ChS (1971) Transportation-location-allocation problems over time. J Reg Sci 11:377-384
Teymourian E, Sadeghi A, Taghipourian F (2011) A dynamic virtual hub location problem in airline networks-formulation and metaheuristic solution approaches. Technology Management Conference (ITMC), IEEE International 1061-1068

Thanh PN, Bostel N, Peton O (2008) A dynamic model for facility location in the design of complex supply chains. Int J Prod Econ 113:678-693

Torres-Soto JE, Uster H (2011) Dynamic-demand capacitated facility location problems with and without relocation. Int J Prod Res 49:3979-4005

VanRoy TJ, Erlenkotter D (1982) A dual-based procedure for dynamic facility location. Manage Sci 28:1091-1105

Wang KJ, Makond B, Liu SY (2011) Location and allocation decisions in a two-echelon supply chain with stochastic demand - a genetic-algorithm based solution. Expert Syst Appl 38:6125-6131

Wen M, Cordeau JF, Laporte G, Larsen J (2010) The dynamic multiperiod vehicle routing problem. Comput Oper Res 37:1615-1623

Wesolowsky GO (1973) Dynamic facility location. Manage Sci 19:1241-1248

Wesolowsky GO, Truscott WG (1975) The multi-period locationallocation problem with relocation of facilities. Manage Sci 22:57-65

Zeballos LJ, Mendez CA, Barbosa-Povoa AP, Novais AQ (2014) Multi-period design and planning of closed-loop supply chains with uncertain supply and demand. Comput Chem Eng 66:151-164 